\title{
Comparative study of results obtained by analysis of structures using ANSYS, STAAD and MATLAB
}

\author{
MihirrSose $^{\mathrm{a}}$, AnimeshDutta $^{\mathrm{b}}$ \\ a Department of Mechanical Engineering, VNIT Nagpur, India \\ ${ }^{b}$ Department of Civil Engineering, VNIT Nagpur, India
}

\begin{abstract}
The analysis of complex structures like frames, trusses and beams is carried out using the Finite Element Method (FEM) in software products like ANSYS and STAAD. The aim of this paper is to compare the deformation results of simple and complex structures obtained using these products. The same structures are also analyzed by a MATLAB program to provide a common reference for comparison. STAAD is used by civil engineers to analyze structures like beams and columns while ANSYS is generally used by mechanical engineers for structural analysis of machines, automobile roll cage, etc. Since both products employ the same fundamental principle of FEM, there should be no difference in their results. Results however, prove contradictory to this for complex structures. Since FEM is an approximate method, accuracy of the solutions cannot be a basis for their comparison and hence, none of the varying results can be termed as better or worse. Their comparison may, however, point to conservative results, significant digits and magnitude of difference so as to enable the analyst to select the software best suited for the particular application of his or her structure.
\end{abstract}

Keywords: ANSYS, comparative, Finite Element Method, MATLAB, STAAD.

\section{Introduction}

The following discussion pertains to finite element analysis of 2 or 3 dimensional skeleton-like structures including trusses, frames, beams, etc. In general, trusses are structures whose elements can resist only axial forces. For practical purposes, all members in this discussion will be treated as beam elements capable of resisting bending moments, howsoever small these moments may be.

Frames are complex structures whose elements are beam elements capable of axial deformations as well. In this discussion, all elements are considered to be 2-noded 3 dimensional elements having 6 degrees of freedom at each node [1].In the local co-ordinate system, the element is oriented such that its length lies along the $x$ axis, while its cross-section lies in the $y z$ plane. Thus at each node, the element is capable of axial deformation (local $x$ axis), transverse deformation (local $y$ and $z$ axes) and rotation (about local $x, y$ and $z$ axes). Since there are two nodes for each element, a 12x12 element stiffness matrix can be formed. This element stiffness matrix can be derived using the rod and beam element theory.

The Finite Element Method is an approximate method that uses computational tools to arrive at the solution of a problem. When the nature of the exact solution of an element is unknown, a simple function is chosen to represent it; this function is known as the interpolation model. The interpolation model is generally a polynomial, due to the ease with which it can be programmed and operated upon by calculus. However, such an interpolation model must satisfy certain convergence conditions in order that the approximate solution so produced, converges to the exact solution on infinitely increasing the number of elements. The interpolation model of a uniaxial 2-noded rod element is thus linear, of the form:

$$
q=a_{0}+a_{1} x
$$

where $q$ is the axial displacement of a node at a distance $x$ from a reference origin, $a_{0}$ and $a_{l}$ are constants determined by boundary conditions of the element. The resulting stiffness matrix of the same element will thus be:

$$
K=(E A / l)\left[\begin{array}{lll}
1 & -1 \\
& -1 & 1
\end{array}\right]
$$

where $K$ denotes the element stiffness matrix, $E$ is the modulus of elasticity of the material of the element, $A$ is the area of cross section of the element and $l$ is the length of the element.

Since it is also a uniaxial phenomenon, the same interpolation model (equation 1.1) is used to determine torsional rotation with $q$ representing the angular displacement at a node. The corresponding stiffness matrix is:

$$
\begin{gathered}
K_{t}=(G J / l)\left[\begin{array}{cc}
1 & -1 \\
-1 & 1
\end{array}\right]
\end{gathered}
$$

where $K_{t}$ is the element stiffness matrix for torsion, $G$ is the shear modulus of the material of the element, $J$ is the polar moment of inertia of the cross section of the material. 
In the case of a 2 dimensional beam element in the $x y$ plane, the interpolation model that satisfies the convergence conditions is:

$$
q=a_{0}+a_{1} x+a_{2} x^{2}+a_{3} x^{3}
$$

where $a_{0}, a_{1}, a_{2}$ and $a_{3}$ are constants determined by the boundary conditions of the element. The stiffness matrix of this beam is:

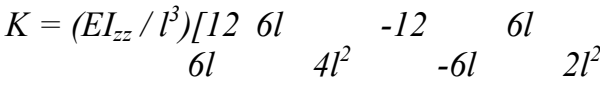

$$
\begin{aligned}
& \begin{array}{llll}
-12 & -6 l & 12 & -6 l
\end{array} \\
& \begin{array}{llll}
6 l & 2 l^{2} & -6 l & \left.4 l^{2}\right]
\end{array}
\end{aligned}
$$

where $I_{z z}$ is the area moment of inertia of the cross section about the $z$ axis.

In order to assemble the stiffness matrix of a 2-noded frame element, we must first assign variables to displacements. Accordingly, $q_{1}, q_{2}$ and $q_{3}$ are the linear deformations of node 1, in the local $x, y$ and $z$ axes. Similarly, $q_{4}, q_{5}$ and $q_{6}$ are the angular deformations of node 1 , about the local $x, y$ and $z$ axes. The deformations $q_{7}$ through $q_{12}$ are the same as above for node 2 of the element. Now $q_{1}$ and $q_{7}$ correspond to the axial deformations of a rod element; hence the positions of $(1,1),(1,7),(7,1)$ and $(7,7)$ in the frame element stiffness matrix are superimposed by the stiffness matrix of a rod element. On the same lines, $q_{2}, q_{6}, q_{8}$ and $q_{12}$ represent the deformations of a rod element in the $x y$ plane and their corresponding locations in the frame element stiffness matrix are superimposed by the stiffness matrix of a 2 dimensional beam element.

\begin{tabular}{|c|c|c|c|c|c|c|c|c|c|c|c|}
\hline$[E A / l$ & 0 & 0 & 0 & 0 & 0 & $\dot{-} \overline{E A / l}$ & 0 & 0 & 0 & 0 & 0 \\
\hline 0 & $12 E I_{z z} / l^{3}$ & 0 & 0 & 0 & $6 E I_{z z} l^{2}$ & 0 & $12 E I_{z z} / l^{3}$ & 0 & 0 & 0 & $6 E I_{z z} / l^{2}$ \\
\hline 0 & 0 & $12 E I_{y y} / l^{3}$ & 0 & $6 \overline{I_{y y}} / l^{2}$ & 0 & 0 & 0 & $12 E I_{y y} / l^{3}$ & 0 & $6 E \overline{I_{y y}} / l^{2}$ & 0 \\
\hline 0 & 0 & 0 & $G J / l$ & 0 & 0 & 0 & 0 & 0 & $\begin{array}{c}-G J / \\
l\end{array}$ & 0 & 0 \\
\hline 0 & 0 & $-6 E I_{y y} / l^{2}$ & 0 & $4 E I_{y y} / l$ & 0 & 0 & 0 & $6 E I_{y y} / l^{2}$ & 0 & $2 E I_{y y} / l$ & 0 \\
\hline 0 & $6 E I_{z z} / l^{2}$ & 0 & 0 & 0 & $4 E I_{z z} / l$ & 0 & $-6 E I_{z z} / l^{2}$ & 0 & 0 & 0 & $2 E I_{z z} / l$ \\
\hline$-E A / l$ & 0 & 0 & 0 & 0 & 0 & $E A / l$ & 0 & 0 & 0 & 0 & 0 \\
\hline 0 & $12 \overline{E I_{z Z}} / l^{3}$ & 0 & 0 & 0 & $6 E \overline{I_{z z}} / l^{2}$ & 0 & $12 E I_{z z} / l^{3}$ & 0 & 0 & 0 & $6 \overline{E I_{z z}} / l^{2}$ \\
\hline 0 & 0 & $\stackrel{-}{12 E I_{y y} / l^{3}}$ & 0 & $6 E I_{y y} / l^{2}$ & 0 & 0 & 0 & $12 E I_{y y} / l^{3}$ & 0 & $6 E I_{y y} / l^{2}$ & 0 \\
\hline 0 & 0 & 0 & $\begin{array}{c}-G J / \\
l\end{array}$ & 0 & 0 & 0 & 0 & 0 & $G J / l$ & 0 & 0 \\
\hline 0 & 0 & $-6 E I_{y y}, l^{2}$ & 0 & $2 E I_{y y} / l$ & 0 & 0 & 0 & $6 E I_{y y} / l^{2}$ & 0 & $4 E I_{y y} / l$ & 0 \\
\hline 0 & $6 E I_{z z} / l^{2}$ & 0 & 0 & 0 & $2 E I_{z z} / l$ & 0 & $-6 E I_{z z} / l^{2}$ & 0 & 0 & 0 & $\left.4 E I_{z z} / l\right]$ \\
\hline
\end{tabular}

Compiling the $12 \times 12$ frame stiffness matrix in the above manner, we get: $\left[K_{f}\right]=$

The above $12 \times 12$ stiffness matrix is formulated with respect to the local co-ordinate system and must be transformed into a global co-ordinate system. The transformation matrix used for this purpose is:

$$
\begin{aligned}
& {[T]=\left[T_{1}\right] \times\left[T_{2}\right]} \\
& \text { where } \quad\left[T_{1}\right]=\left[\begin{array}{llll}
l_{x} & m_{x} & n_{x}
\end{array}\right. \\
& \begin{array}{lll}
-\left(l_{x} m_{x}\right) / d & \left(l_{x}+n_{x}\right) / d & -\left(m_{x} n_{x}\right) / d
\end{array} \\
& \text { where, } \quad-n_{x} / d \quad 001
\end{aligned}
$$

and $l_{x}, m_{x}$ and $n_{x}$ are the direction cosines of the local $x$ axis with respect to the global $X, Y$ and $Z$ axes,

where

$$
\left[T_{2}\right]=\quad \begin{array}{ccc}
1 & 0 & 0 \\
0 & \cos a & \sin a
\end{array}
$$

$0 \cos a \sin a$

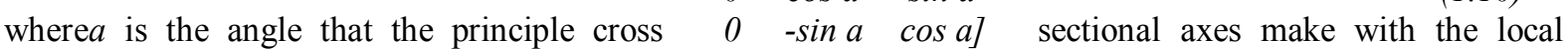
axes.

The global stiffness matrix is thus compiled as:

$$
\left[K_{\text {global }}\right]=[T]^{T}\left[K_{f}\right][T]
$$

The element stiffness matrix thus compiled can now be used to calculate the linear and angular deformation at each node using the following relation:

$$
[P]=\left[K_{\text {global }}[Q]\right.
$$

where $[P]$ is the load matrix indicating the force or moment applied on particular degrees of freedom of particular nodes and $[Q]$ is the deformation matrix. In all the cases pertaining to this paper, the load matrix is known, the global stiffness matrix is compiled using the given data and the deformation matrix is the unknown 
quantity. Hence, rearranging the equation 1.12 we can separate the known quantities from the unknown ones as follows:

$$
[Q]=\left[K_{\text {global }}\right]^{-1}[P]
$$

\section{Matlab Program}

The matlab programs written in order to solve the particular type of problems pertaining to this paper consist of three main parts, the data, body and solution. The data consists of discretizing the structure into nodes and assigning co-ordinates to its respective node. The body of the program creates the global stiffness matrix of the structure while the solution part assigns load values and constraints to the corresponding nodes and calculates the displacement matrix using equation 1.13.

Shown below is a sample matlab program for a single, 2-noded L-section beam element. The element of length $500 \mathrm{~mm}$ lies on the $x$ axis and the cross section is an equal leg angle section of 50x50x5. All degrees of freedom are constrained at node 1 i.e. at the origin and a load of $10 \mathrm{kN}$ is applied at node 2 i.e. at the free end of the element. The value of moments of inertia and area of the cross section are taken from the Bureau of Indian Standards (BIS) handbook.

\section{$\%$ 3-D 2 NODED BEAM ANALYSIS - L SECTION}

clear

clc

$\mathrm{Al}=479$

$\mathrm{Il}=110000$

$\mathrm{Jl}=2 * \mathrm{Il}$

$\mathrm{E}=205000$

$\mathrm{G}=80000$

$\mathrm{x}(1)=0$;

$x(2)=500$;

$\mathrm{y}(1)=0$;

$y(2)=0$

$\mathrm{z}(1)=0$

$z(2)=0$;

le $=\operatorname{sqrt}\left((\mathrm{x}(2)-\mathrm{x}(1))^{\wedge} 2+(\mathrm{y}(2)-\mathrm{y}(1))^{\wedge} 2+(\mathrm{z}(2)-\mathrm{z}(1))^{\wedge} 2\right) ;$

$1=(\mathrm{x}(2)-\mathrm{x}(1)) / \mathrm{le}$;

$\mathrm{m}=(\mathrm{y}(2)-\mathrm{y}(1)) / \mathrm{le}$;

$\mathrm{n}=(\mathrm{z}(2)-\mathrm{z}(1)) / \mathrm{le} ;$

$\mathrm{d}=\operatorname{sqrt}\left(\left(1^{\wedge} 2\right)+\left(\mathrm{n}^{\wedge} 2\right)\right)$

$\mathrm{Te}=\mathrm{Al} * \mathrm{E} / \mathrm{le}$

$\mathrm{Be}=\mathrm{E} * \mathrm{Il} /\left(\mathrm{l}^{\wedge} 3\right)$;

Klocal $=K_{f}$

$\mathrm{Y} 1=\left[1 \mathrm{~m} \mathrm{n} ;\left(-1^{*} \mathrm{~m} / \mathrm{d}\right)\left(\left(\left(1^{\wedge} 2\right)+\left(\mathrm{n}^{\wedge} 2\right)\right) / \mathrm{d}\right)\left(-\mathrm{m}^{*} \mathrm{n} / \mathrm{d}\right) ;(-\mathrm{n} / \mathrm{d}) 0(1 / \mathrm{d})\right]$;

$\mathrm{Y}=\operatorname{zeros}(12,12)$;

for $\mathrm{h}=1: 3: 12$

$\mathrm{Y}(\mathrm{h}:(\mathrm{h}+2), \mathrm{h}:(\mathrm{h}+2))=\mathrm{Y} 1$;

end

Klocal $=\mathrm{Y}^{\prime} *$ Klocal $* \mathrm{Y}$;

fprintf('In STIFFNESS MATRIX: $\backslash n ')$

$\operatorname{disp}($ Klocal);

$\%$ POINT LOAD at Specific Nodes on the Rod

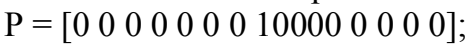

$\mathrm{P}=\mathrm{P}^{\prime}$

$\%$ DISPLACEMENT MATRIX

$\mathrm{Ke}=\mathrm{Klocal}$

$\mathrm{Pe}=\mathrm{P}$

for $\mathrm{i}=1: 6$

$\operatorname{Ke}(1,:)=[]$

$\operatorname{Ke}(:, 1)=[] ;$

$\operatorname{Pe}(1,:)=[]$;

end

$\mathrm{Qe}=\mathrm{Ke} \backslash \mathrm{Pe}$;

$\mathrm{Q}=\operatorname{zeros}(12,1)$;

$\mathrm{Q}(7: 12,:)=\mathrm{Qe}$; 
fprintf('In DISPLACEMENT MATRIX : \n')

$\operatorname{disp}(\mathrm{Q})$

The output of the above program is as follows:

(The unit of the stiffness matrix is $\mathrm{N} / \mathrm{mm}$ and that of the displacement matrix is $\mathrm{mm}$ henceforth)

\section{STIFFNESS MATRIX:}

$1.0 \mathrm{e}+008 *$

Columns 1 through 6

$\begin{array}{rrrrrr}0.0020 & 0 & 0 & 0 & 0 & 0 \\ 0 & 0.0000 & 0 & 0 & 0 & 0.0054 \\ 0 & 0 & 0.0000 & 0 & -0.0054 & 0 \\ 0 & 0 & 0 & 0.3520 & 0 & 0 \\ 0 & 0 & -0.0054 & 0 & 1.8040 & 0 \\ 0 & 0.0054 & 0 & 0 & 0 & 1.8040 \\ -0.0020 & 0 & 0 & 0 & 0 & 0 \\ 0 & -0.0000 & 0 & 0 & 0 & -0.0054 \\ 0 & 0 & -0.0000 & 0 & 0.0054 & 0 \\ 0 & 0 & 0 & -0.3520 & 0 & 0 \\ 0 & 0 & -0.0054 & 0 & 0.9020 & 0 \\ 0 & 0.0054 & 0 & 0 & 0 & 0.9020\end{array}$

Columns 7 through 12

$\begin{array}{rrrrcr}-0.0020 & 0 & 0 & 0 & 0 & 0 \\ 0 & -0.0000 & 0 & 0 & 0 & 0.0054 \\ 0 & 0 & -0.0000 & 0 & -0.0054 & 0 \\ 0 & 0 & 0 & -0.3520 & 0 & 0 \\ 0 & 0 & 0.0054 & 0 & 0.9020 & 0 \\ 0 & -0.0054 & 0 & 0 & 0 & 0.9020 \\ 0.0020 & 0 & 0 & 0 & 0 & 0 \\ 0 & 0.0000 & 0 & 0 & 0 & -0.0054 \\ 0 & 0 & 0.0000 & 0 & 0.0054 & 0 \\ 0 & 0 & 0 & 0.3520 & 0 & 0 \\ 0 & 0 & 0.0054 & 0 & 1.8040 & 0 \\ 0 & -0.0054 & 0 & 0 & 0 & 1.8040\end{array}$

DISPLACEMENT MATRIX:

0
0
0
0
0
0
0
8775
0
0
0
0554

III. Comparison Of Results

In this discussion the ANSYS and STAAD solutions for the deformation of structure are compared to that of MATLAB. This comparison is in no way an indication of the accuracy of the results provided by any of the mentioned software products. The MATLAB program simply provides a suitable reference for comparison. In order to develop an overview of the results, structures of varying complexities are analyzed and conclusions 
drawn from them individually and together.For STAAD, the cross section data: area and moments of inertia have been input manually in order to maintain uniformity of value through all media of analyses. For all structural analyses pertaining to this article:

Modulus of elasticity $=205000 \mathrm{~N} / \mathrm{mm}^{2}$

Poisons ratio $=0.3$

All the relevant units are in $\mathrm{N}, \mathrm{mm}$ and rad.

\subsection{Example 1}

The ANSYS solution of the matlab program mentioned in section 2 is given below. This simple beam element allows for a comparison on the elementary scale.

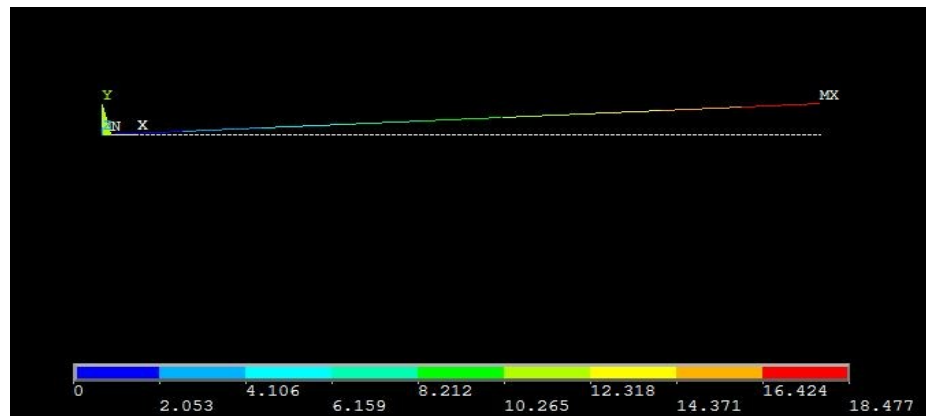

Figure 3.1.1Displacement of beam plotted in ANSYS.The dotted line represents original beam and the colored line represents the deformed shape, with $M X$ showing the point of maximum deformation.

\begin{tabular}{lcccc} 
NODE & UX & UY & UZ & USUM \\
1 & 0.0000 & 0.0000 & 0.0000 & 0.0000 \\
2 & 0.0000 & 18.477 & 0.0000 & 18.477 \\
& \multicolumn{5}{c}{} \\
NODE & ROTX & ROTY & ROTZ & RSUM \\
1 & 0.0000 & 0.0000 & 0.0000 & 0.0000 \\
2 & 0.0000 & 0.0000 & $0.55432 \mathrm{E}-01$ & $0.55432 \mathrm{E}-01$
\end{tabular}

The STAAD solution is:

Figure 3.1.2Displacement of beam plotted in STAAD. The white line represents original beam and the green line represents the deformed shape.

\section{JOINT LOAD X-TRANS Y-TRANS Z-TRANS X-ROTAN Y-ROTAN Z-ROTAN}

$\begin{array}{lllllllll}1 & 1 & 0.0000 & 0.0000 & 0.0000 & 0.0000 & 0.0000 & 0.0000 & \\ 2 & 1 & & 0.0000 & 18.477 & 0.0000 & 0.0000 & 0.0000 & 0.0554\end{array}$

The above solutions match almost exactly except for the difference in the significant digits of the deformation in $y$ direction according to the MATLAB results and the rotation about the $z$ axis as per the ANSYS results. For all practical purposes, the deformation results of the cantilever beam are same by all three media.

\subsection{Example 2: Plane Frame}

Next, we consider a simple planar structure consisting of 3 members and 4 nodes. Nodes 1 and 4 are fixed with respect to all the degrees of freedom and a load of $10 \mathrm{kN}$ is applied on node 2 along the direction of 
the positive $x$ axis. The members 1 and 3 have hollow circular cross section of outer diameter $273 \mathrm{~mm}$ and inner diameter $261 \mathrm{~mm}$, while the $2^{\text {nd }}$ member has hollow circular cross section of outer diameter $219.1 \mathrm{~mm}$ and inner diameter $207.1 \mathrm{~mm}$. The entire structure lies in the $x y$ plane. The 3 members are vertical, horizontal and vertical respectively with a length of 6000,5000 and $6000 \mathrm{~mm}$ respectively.

Table 3.2.1

\begin{tabular}{|c|cccccc|}
\hline & \multicolumn{7}{|c|}{ MATLAB RESULTS } \\
\hline NODE & $\mathbf{u x}$ & uy & uz & rotx & roty & rotz \\
\hline 1 & 0 & 0 & 0 & 0 & 0 & 0 \\
2 & 16.1218 & 0.0274 & 0 & 0 & 0 & -0.0021 \\
3 & 16.0915 & -0.0274 & 0 & 0 & 0 & -0.0021 \\
4 & 0 & 0 & 0 & 0 & 0 & 0 \\
\hline
\end{tabular}

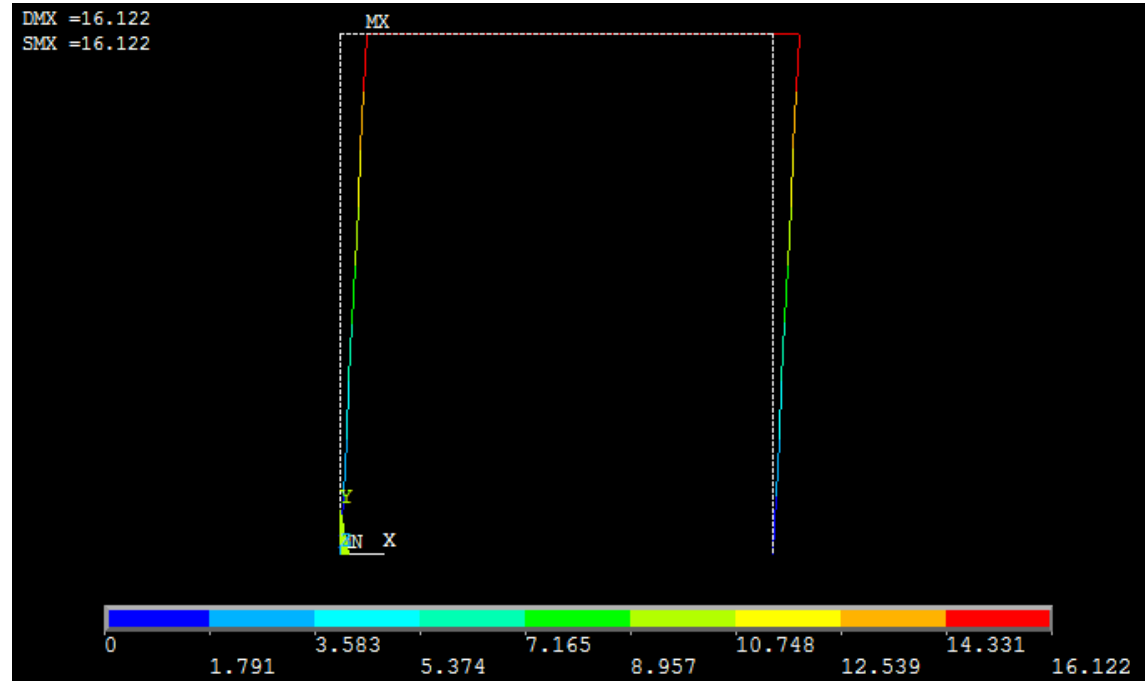

Figure 3.2.1 Plane Frame displacement plotted in ANSYS. The dotted line represents original beam and the colored line represents the deformed shape, with $M X$ showing the point of maximum resultant deformation.

Table 3.2.2

\begin{tabular}{|c|cccccc|}
\hline & \multicolumn{6}{|c|}{ ANSYS RESULTS } \\
\hline NODE & ux & uy & uz & rotx & roty & rotz \\
\hline 1 & 0 & 0 & 0 & 0 & 0 & 0 \\
2 & 16.122 & 0.0274 & 0 & 0 & 0 & -0.0021 \\
3 & 16.091 & -0.0274 & 0 & 0 & 0 & -0.0021 \\
4 & 0 & 0 & 0 & 0 & 0 & 0 \\
\hline
\end{tabular}

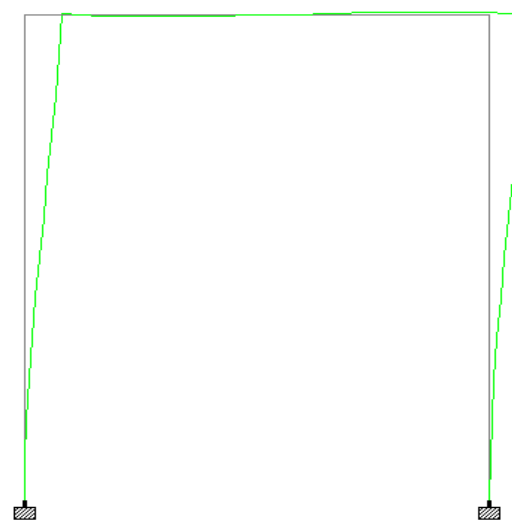

Figure 3.2.2 Plane Frame displacement plotted in STAAD. The white line represents original beam and the green line represents the deformed shape. 
Table 3.2.3

\begin{tabular}{|c|cccccc|}
\hline & \multicolumn{6}{|c|}{ STAAD RESULTS } \\
\hline NODE & $\mathbf{u x}$ & uy & uz & rotx & roty & rotz \\
\hline 1 & 0 & 0 & 0 & 0 & 0 & 0 \\
2 & 16.122 & 0.027 & 0 & 0 & 0 & -0.0021 \\
3 & 16.091 & -0.027 & 0 & 0 & 0 & -0.0021 \\
4 & 0 & 0 & 0 & 0 & 0 & 0 \\
\hline
\end{tabular}

It can be seen from the above Tables $(3.2 .1-3.2 .3)$ that the ANSYS and STAAD results vary slightly from the MATLAB results. This variation can be quantified by charting the error with respect to the MATLAB solution.

Table 3.2.4

\begin{tabular}{|c|cccccc|}
\hline & \multicolumn{6}{|c|}{ ANSYS ERROR in \% } \\
\hline NODE & Ex & Ey & Ez & Erotx & Eroty & Erotz \\
\hline 1 & 0 & 0 & 0 & 0 & 0 & 0 \\
2 & -0.00124 & 0 & 0 & 0 & 0 & 0 \\
3 & 0.003107 & 0 & 0 & 0 & 0 & 0 \\
4 & 0 & 0 & 0 & 0 & 0 & 0 \\
\hline
\end{tabular}

Table 3.2 .5

\begin{tabular}{|c|cccccc|}
\hline & \multicolumn{7}{|c|}{ STAAD ERROR in \% } \\
\hline NODE & Ex & Ey & Ez & Erotx & Eroty & Erotz \\
\hline 1 & 0 & 0 & 0 & 0 & 0 & 0 \\
2 & -0.00124 & 1.459854 & 0 & 0 & 0 & 0 \\
3 & 0.003107 & 1.459854 & 0 & 0 & 0 & 0 \\
4 & 0 & 0 & 0 & 0 & 0 & 0 \\
\hline
\end{tabular}

From the Tables 3.2.4 and 3.2.5, we can see that there is a very small error in the STAAD and ANSYS results for deformation along the $x$ axis. The STAAD error in deformation along $y$ axis is about $1.5 \%$; however, from Tables 3.2.1 - 3.2.3 we can see that error in both, STAAD and ANSYS results is due to the difference in significant digits and suitable rounding off of deformation values of MATLAB results will give us exactly matching results.

\subsection{Example 3: Space Frame}

Similar to the previous example in article 3.2, we consider a spatial structure with 3 members and 4 nodes. The cross section of the members used and the load vector is the same as that of the previous example. The co-ordinates of the 4 nodes are $(0,0,0),(0,6000,0),(5000,6000,5000)$ and $(5000,0,5000)$ respectively. All distances are in $\mathrm{mm}$.

Table 3.3.1

\begin{tabular}{|c|cccccc|}
\hline & \multicolumn{7}{|c|}{ MATLAB RESULTS } \\
\hline NODE & $\mathbf{u x}$ & $\mathbf{u y}$ & $\mathbf{u z}$ & $\mathbf{r o t x}$ & roty & rotz \\
\hline 1 & 0 & 0 & 0 & 0 & 0 & 0 \\
2 & 38.3104 & 0.0126 & -20.3157 & -0.0056 & -0.003 & -0.0083 \\
3 & 18.7996 & -0.0126 & -0.8478 & -0.0014 & -0.003 & -0.0042 \\
4 & 0 & 0 & 0 & 0 & 0 & 0 \\
\hline
\end{tabular}




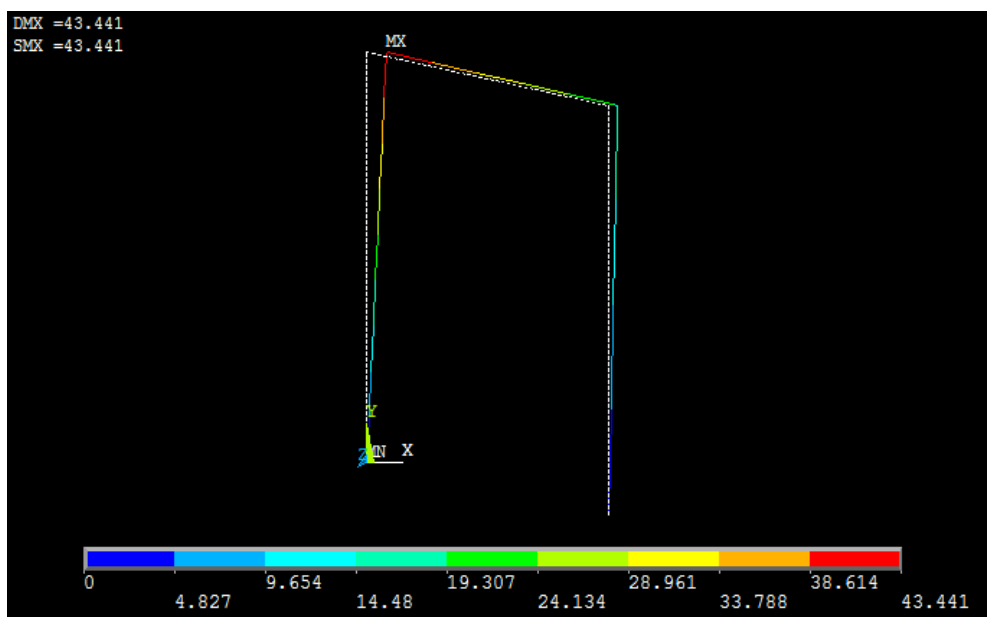

Figure 3.3.1 Space Frame resultant displacement plotted in ANSYS. The dotted line represents original beam and the colored line represents the deformed shape, with $M X$ showing the point of maximum resultant deformation.

Table 3.3.2

\begin{tabular}{|c|cccccc|}
\hline & \multicolumn{7}{|c|}{ ANSYS RESULTS } \\
\hline NODE & $\mathbf{u x}$ & uy & $\mathbf{u z}$ & rotx & roty & rotz \\
\hline 1 & 0 & 0 & 0 & 0 & 0 & 0 \\
2 & 38.368 & 0.0126 & -20.373 & -0.00563 & -0.003 & -0.00836 \\
3 & 18.742 & -0.0126 & -0.79 & -0.00143 & -0.003 & -0.00415 \\
4 & 0 & 0 & 0 & 0 & 0 & 0 \\
\hline
\end{tabular}

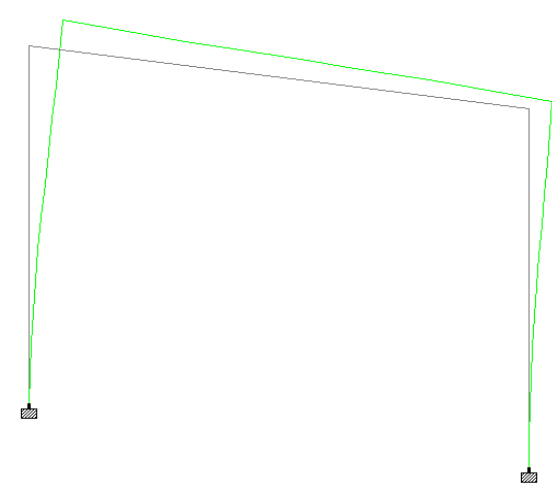

Figure 3.3.2 Space Frame displacement plotted in STAAD. The white line represents original beam and the green line represents the deformed shape.

Table 3.3.3

\begin{tabular}{|c|cccccc|}
\hline & \multicolumn{7}{|c|}{ STAAD RESULTS } \\
\hline NODE & ux & uy & uz & rotx & roty & rotz \\
\hline 1 & 0 & 0 & 0 & 0 & 0 & 0 \\
2 & 38.368 & 0.013 & -20.373 & -0.0056 & -0.003 & -0.0084 \\
3 & 18.742 & -0.013 & -0.79 & -0.0014 & -0.003 & -0.0042 \\
4 & 0 & 0 & 0 & 0 & 0 & 0 \\
\hline
\end{tabular}

The above tables (3.3.1 - 3.3.3) show a difference between the deformation results of MATLAB and those of STAAD and ANSYS. The magnitude of difference distinctly varies for each degree of freedom, as we can see from the error tables 3.3.4 and 3.3.5 shown below. The error tables 3.3.4 and 3.3.5 are tabulated using the modulus of the values in tables 3.3.2 and 3.3.3 respectively in order to chart the magnitude of variation. The positive or negative sign of the displacement values is only an indication of the corresponding direction of displacement along or about the particular axis. The positive or negative sign of the error values however indicates whether the magnitude of the particular ANSYS or STAAD displacement value is greater than or less 
than its corresponding MATLAB value, respectively. This helps us draw direct inferences on whether a value is conservative or not.

Table 3.3.4

\begin{tabular}{|c|cccccc|}
\hline & \multicolumn{6}{|c|}{ ANSYS ERROR in \% } \\
\hline NODE & Ex & Ey & Ez & Erotx & Eroty & Erotz \\
\hline 1 & 0 & 0 & 0 & 0 & 0 & 0 \\
2 & -0.15035 & 0 & -0.28205 & -0.53571 & 0 & -0.72289 \\
3 & 0.306389 & 0 & 6.817646 & -2.14286 & 0 & 1.190476 \\
4 & 0 & 0 & 0 & 0 & 0 & 0 \\
\hline
\end{tabular}

Table 3.3.5

\begin{tabular}{|c|cccccc|}
\hline & \multicolumn{7}{|c|}{ STAAD ERROR in \% } \\
\hline NODE & Ex & Ey & Ez & Erotx & Eroty & Erotz \\
\hline 1 & 0 & 0 & 0 & 0 & 0 & 0 \\
2 & -0.15035 & -3.1746 & -0.28205 & 0 & 0 & -1.20482 \\
3 & 0.306389 & -3.1746 & 6.817646 & 0 & 0 & 0 \\
4 & 0 & 0 & 0 & 0 & 0 & 0 \\
\hline
\end{tabular}

From the tables 3.3.1 - 3.3.3, we can see that the STAAD and ANSYS results are nearly identical for all degrees of freedom. Any difference in their values is observed to be due to rounding off in the STAAD value ( $u y$, rotx and rotz). This observation can also be made when comparing the same values (for both STAAD and ANSYS) with their corresponding MATLAB results. The deformations along $x$ and $z$ axesaccording to the MATLAB program do not match those of ANSYS and STAAD. The error is quite substantial for the $z$ axis deformation of node 3 as shown in tables 3.3.4 and 3.3.5. There is neither any discernible pattern within the error nor is the error consistently conservative. This error may be attributed to cumulative rounding off effect, which increases with increase in the number of nodes.

\subsection{Example 4: 3-D Structure}

In practice, software like ANSYS and STAAD are used to analyze 3 dimensional frames or structures with multiple nodes and elements. Such a structure is analyzed in this section. This structure is an overhead truss supported by 2 columns on both its ends.

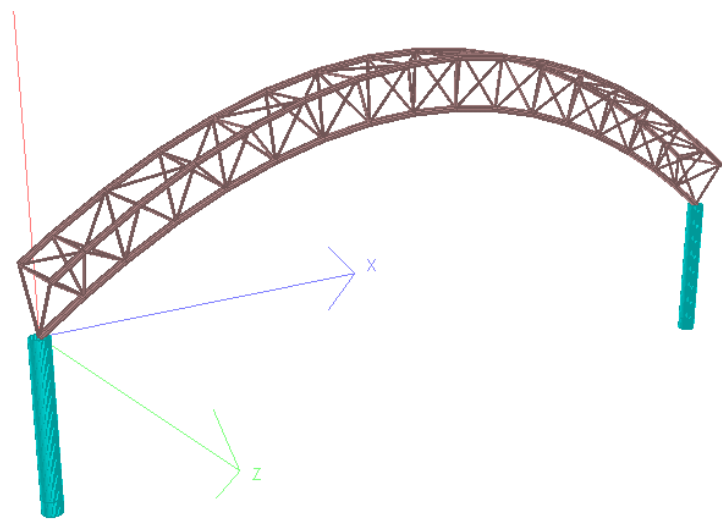

Figure 3.4.1 STAAD model of structure

This structure consists of 52 nodes and 150 members of varying cross section. The nodal distribution is shown in image 3.4.2. 


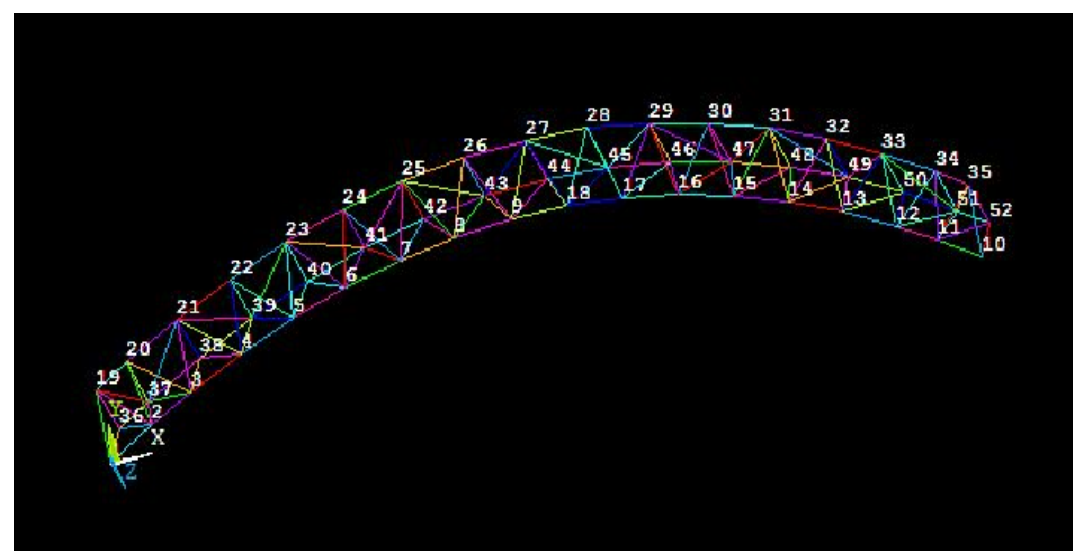

Figure 3.4.2 Nodal distribution of structure as modeled in ANSYS

The structure is subjected to 3 types of loads: dead load, other load and live load. The analysis however, is carried out for 2 cases:

1. $1.5 \times($ dead load + other load + live load $)$

2. dead load + other load + live load

The first case is used for design purposes and the second to estimate actual deformations.

The MATLAB program details the member indices and their respective cross section details along with the nodal distribution of each type of load. The units throughout this program are $\mathrm{kN}$ and $\mathrm{m}$.

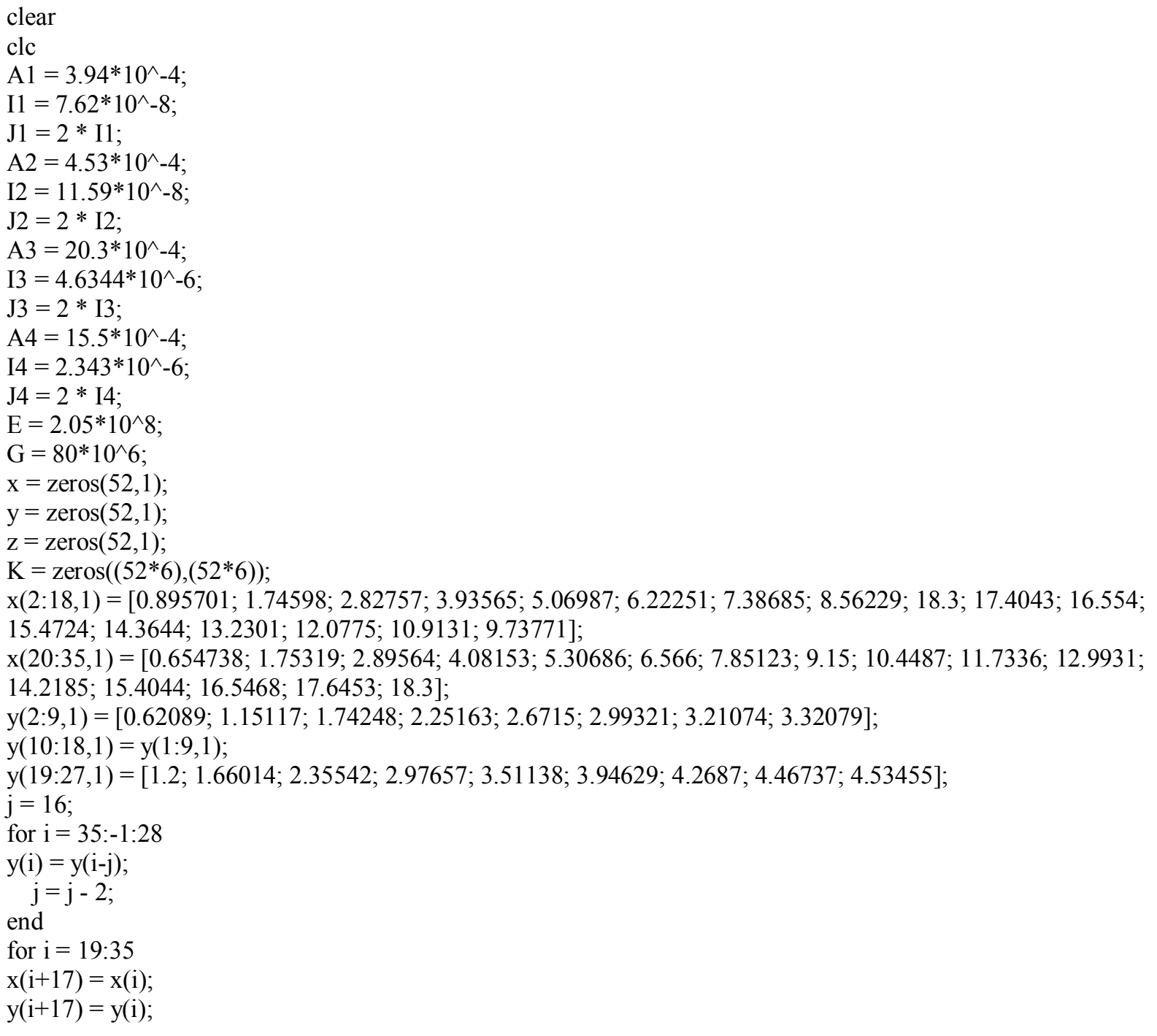




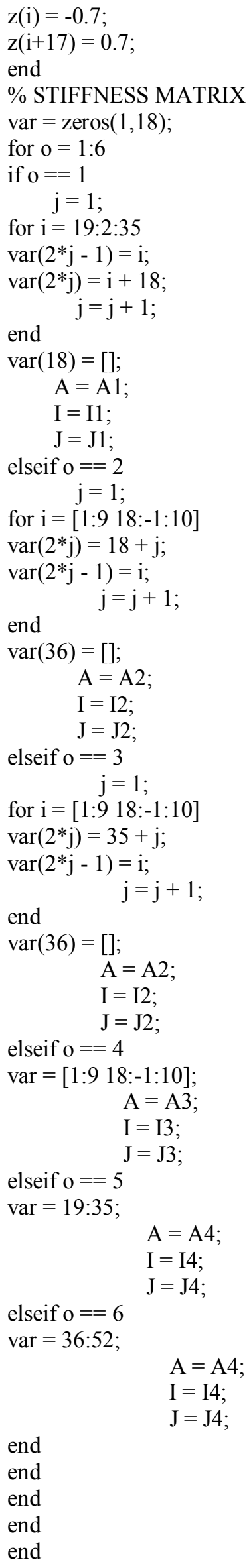


end

for $\mathrm{i}=1$ :(length(var)-1)

$\mathrm{j}=\operatorname{var}(\mathrm{i})$;

$\mathrm{k}=\operatorname{var}(\mathrm{i}+1)$;

le $=\operatorname{sqrt}\left((\mathrm{x}(\mathrm{k})-\mathrm{x}(\mathrm{j}))^{\wedge} 2+(\mathrm{y}(\mathrm{k})-\mathrm{y}(\mathrm{j}))^{\wedge} 2+(\mathrm{z}(\mathrm{k})-\mathrm{z}(\mathrm{j}))^{\wedge} 2\right)$

$1=(\mathrm{x}(\mathrm{k})-\mathrm{x}(\mathrm{j})) / \mathrm{le}$;

$\mathrm{m}=(\mathrm{y}(\mathrm{k})-\mathrm{y}(\mathrm{j})) / \mathrm{le}$;

$\mathrm{n}=(\mathrm{z}(\mathrm{k})-\mathrm{z}(\mathrm{j})) / \mathrm{le}$;

$\mathrm{d}=\operatorname{sqrt}\left(\left(1^{\wedge} 2\right)+\left(\mathrm{n}^{\wedge} 2\right)\right)$

$\mathrm{Te}=\mathrm{A} * \mathrm{E} / \mathrm{le}$

$\mathrm{Be}=\mathrm{E} * \mathrm{I} /\left(\mathrm{le}^{\wedge} 3\right)$

Klocal $=K_{f}$

$\mathrm{Y} 1=\left[1 \mathrm{~m} \mathrm{n} ;\left(-1^{*} \mathrm{~m} / \mathrm{d}\right)\left(\left(\left(1^{\wedge} 2\right)+\left(\mathrm{n}^{\wedge} 2\right)\right) / \mathrm{d}\right)\left(-\mathrm{m}^{*} \mathrm{n} / \mathrm{d}\right) ;(-\mathrm{n} / \mathrm{d}) 0(\mathrm{l} / \mathrm{d})\right]$;

..equation 1.6

$\mathrm{Y}=\operatorname{zeros}(12,12)$

for $h=1: 3: 12$

$\mathrm{Y}(\mathrm{h}:(\mathrm{h}+2), \mathrm{h}:(\mathrm{h}+2))=\mathrm{Y} 1$;

end

Klocal $=\mathrm{Y}^{\prime} *$ Klocal $* \mathrm{Y}$;

$\mathrm{K}((6 * \mathrm{j}-5): 6 * \mathrm{j},(6 * \mathrm{j}-5): 6 * \mathrm{j})=\mathrm{K}((6 * \mathrm{j}-5): 6 * \mathrm{j},(6 * \mathrm{j}-5): 6 * \mathrm{j})+\operatorname{Klocal}(1: 6,1: 6) ;$

$\mathrm{K}\left((6 * \mathrm{j}-5): 6^{* \mathrm{j}},\left(6^{*} \mathrm{k}-5\right): 6^{*} \mathrm{k}\right)=\mathrm{K}\left(\left(6^{* \mathrm{j}-5}\right): 6^{* \mathrm{j}},(6 * \mathrm{k}-5): 6^{*} \mathrm{k}\right)+\mathrm{Klocal}(1: 6,7: 12) ;$

$\mathrm{K}((6 * \mathrm{k}-5): 6 * \mathrm{k},(6 * \mathrm{j}-5): 6 * \mathrm{j})=\mathrm{K}\left(\left(6^{*} \mathrm{k}-5\right): 6^{*} \mathrm{k},(6 * \mathrm{j}-5): 6 * \mathrm{j}\right)+\operatorname{Klocal}(7: 12,1: 6)$

$\mathrm{K}\left(\left(6^{*} \mathrm{k}-5\right): 6^{*} \mathrm{k},(6 * \mathrm{k}-5): 6^{*} \mathrm{k}\right)=\mathrm{K}\left(\left(6^{*} \mathrm{k}-5\right): 6^{*} \mathrm{k},\left(6^{*} \mathrm{k}-5\right): 6^{*} \mathrm{k}\right)+\mathrm{K} \operatorname{local}(7: 12,7: 12)$;

end

end

for $o=19: 35$

$\operatorname{var}=[\mathrm{o}(\mathrm{o}+17)]$

for $\mathrm{i}=1$ :(length(var)-1)

$\mathrm{j}=\operatorname{var}(\mathrm{i})$;

$\mathrm{k}=\operatorname{var}(\mathrm{i}+1)$;

le $\left.=\operatorname{sqrt}\left((x(k)-x(j))^{\wedge} 2+(y(k)-y(j))^{\wedge} 2+(z(k)-z(j))\right)^{\wedge}\right)$

$\mathrm{l}=(\mathrm{x}(\mathrm{k})-\mathrm{x}(\mathrm{j})) / \mathrm{le}$;

$\mathrm{m}=(\mathrm{y}(\mathrm{k})-\mathrm{y}(\mathrm{j})) / \mathrm{le}$;

$\mathrm{n}=(\mathrm{z}(\mathrm{k})-\mathrm{z}(\mathrm{j})) / \mathrm{le}$;

$\mathrm{d}=\operatorname{sqrt}\left(\left(1^{\wedge} 2\right)+\left(\mathrm{n}^{\wedge} 2\right)\right)$

$\mathrm{Te}=\mathrm{A} 1 * \mathrm{E} / \mathrm{le}$;

$\mathrm{Be}=\mathrm{E}^{*} \mathrm{I} 1 /\left(\mathrm{le}^{\wedge} 3\right) ;$

Klocal $=K_{f}$

$\mathrm{Y} 1=\left[1 \mathrm{~m} \mathrm{n} ;\left(-1^{*} \mathrm{~m} / \mathrm{d}\right)\left(\left(\left(1^{\wedge} 2\right)+\left(\mathrm{n}^{\wedge} 2\right)\right) / \mathrm{d}\right)\left(-\mathrm{m}^{*} \mathrm{n} / \mathrm{d}\right) ;(-\mathrm{n} / \mathrm{d}) 0(1 / \mathrm{d})\right]$

...equation 1.6

$\mathrm{Y}=\operatorname{zeros}(12,12)$;

for $\mathrm{h}=1: 3: 12$

$\mathrm{Y}(\mathrm{h}:(\mathrm{h}+2), \mathrm{h}:(\mathrm{h}+2))=\mathrm{Y} 1$;

end

Klocal $=\mathrm{Y}^{\prime} *$ Klocal $* \mathrm{Y}$;

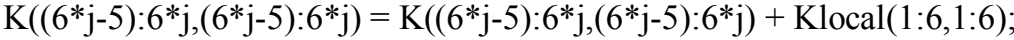

$\mathrm{K}((6 * \mathrm{j}-5): 6 * \mathrm{j},(6 * \mathrm{k}-5): 6 * \mathrm{k})=\mathrm{K}((6 * \mathrm{j}-5): 6 * \mathrm{j},(6 * \mathrm{k}-5): 6 * \mathrm{k})+\mathrm{Klocal}(1: 6,7: 12)$;

$\mathrm{K}((6 * \mathrm{k}-5): 6 * \mathrm{k},(6 * \mathrm{j}-5): 6 * \mathrm{j})=\mathrm{K}((6 * \mathrm{k}-5): 6 * \mathrm{k},(6 * \mathrm{j}-5): 6 * \mathrm{j})+\mathrm{Klocal}(7: 12,1: 6) ;$

$\mathrm{K}((6 * \mathrm{k}-5): 6 * \mathrm{k},(6 * \mathrm{k}-5): 6 * \mathrm{k})=\mathrm{K}((6 * \mathrm{k}-5): 6 * \mathrm{k},(6 * \mathrm{k}-5): 6 * \mathrm{k})+\mathrm{Klocal}(7: 12,7: 12)$;

end

end

fprintf(' $\backslash n$ STIFFNESS MATRIX: \n')

$\operatorname{disp}(\mathrm{K})$

$\%$ POINT LOAD at Specific Nodes on the Rod

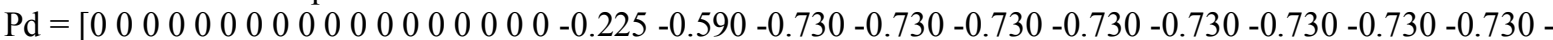
$0.730-0.730-0.730-0.730-0.730-0.590-0.225-0.225-0.590-0.730-0.730-0.730-0.730-0.730-0.730-0.730$ $-0.730-0.730-0.730-0.730-0.730-0.730-0.590-0.225]$

$\mathrm{Po}=[0-1.770-1.770-1.770-1.770-1.770-1.770-1.770-1.7700-1.770-1.770-1.770-1.770-1.770-1.770-$

$1.770-1.7700000000000000000000000000000000000000000000]$; 


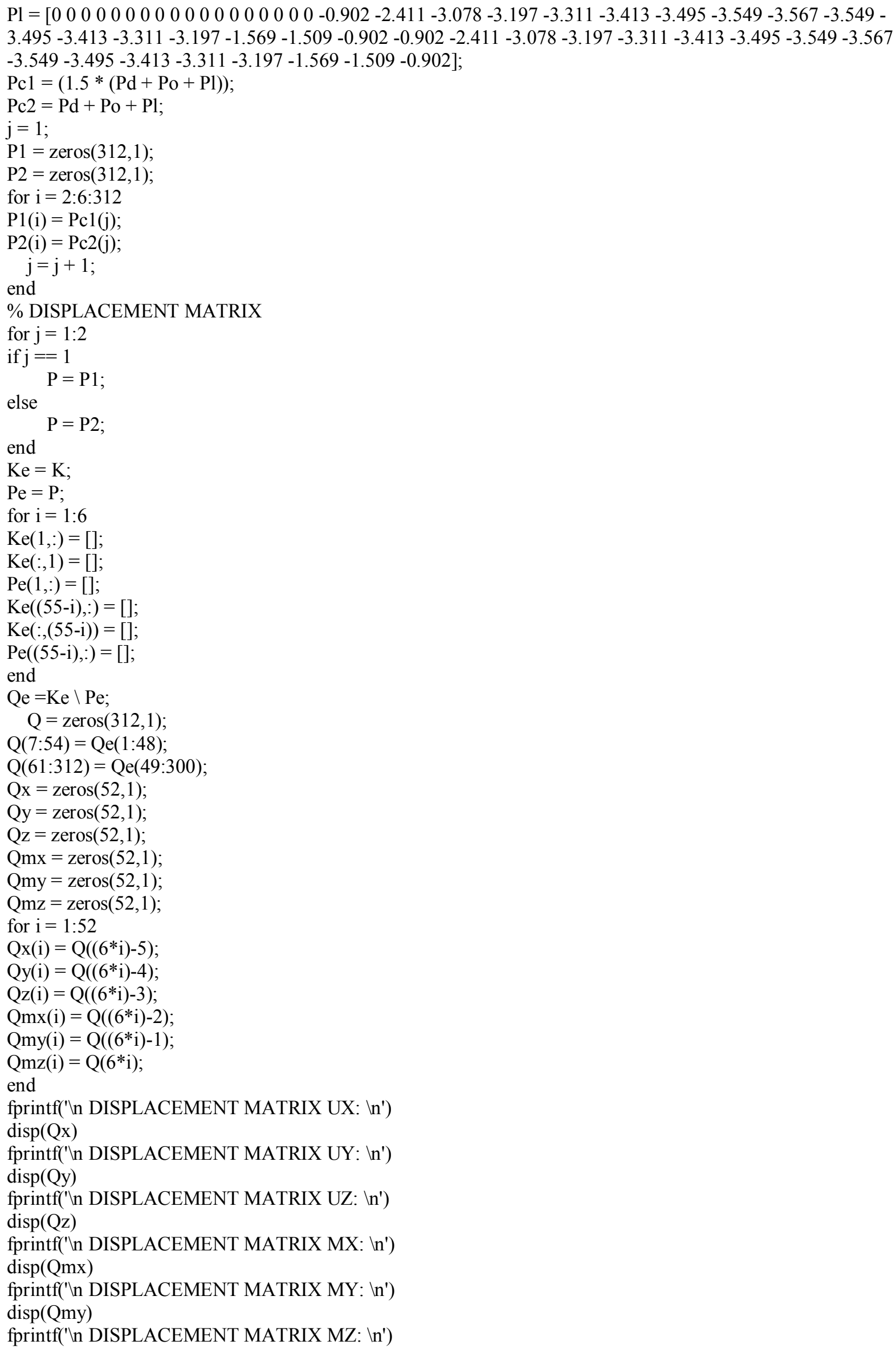


$\operatorname{disp}(\mathrm{Qmz})$

end

The ANSYS and STAAD results of the analysis of the structure are tabulated along with those of MATLAB. The units for the same are $\mathrm{mm}$ and radian.

\subsubsection{Load Case 1}

Table 3.4.1.1

\begin{tabular}{|c|c|c|c|c|c|c|}
\hline \multirow[b]{2}{*}{ NODE } & \multicolumn{6}{|c|}{ MATLAB RESULTS - 1} \\
\hline & $\mathbf{u x}$ & uy & $\mathbf{u z}$ & rotx & roty & rotz \\
\hline 1 & 0 & 0 & 0 & 0 & 0 & 0 \\
\hline 2 & -0.2256 & -0.3345 & -0.00214 & $-1.81 \mathrm{E}-06$ & $3.37 \mathrm{E}-06$ & -0.000331 \\
\hline 3 & -0.1997 & -0.9344 & -0.00569 & $-4.53 \mathrm{E}-06$ & $-3.9 \mathrm{E}-07$ & -0.000584 \\
\hline 4 & -0.0957 & -1.7042 & -0.00585 & $-1.82 \mathrm{E}-06$ & $1.2 \mathrm{E}-07$ & -0.000601 \\
\hline 5 & 0.0391 & -2.4922 & -0.00986 & $-5.49 \mathrm{E}-06$ & 7.1E-07 & -0.000623 \\
\hline 6 & 0.1473 & -3.2188 & -0.00951 & $-2.42 \mathrm{E}-06$ & $-1.43 \mathrm{E}-06$ & -0.000543 \\
\hline 7 & 0.1994 & -3.81 & -0.01219 & $-4.8 \mathrm{E}-06$ & $1.73 \mathrm{E}-06$ & -0.000413 \\
\hline 8 & 0.1936 & -4.2153 & -0.01187 & -0.000003 & $-2.1 \mathrm{E}-06$ & -0.000246 \\
\hline 9 & 0.1468 & -4.4038 & -0.01277 & $-3.77 \mathrm{E}-06$ & $2.18 \mathrm{E}-06$ & $-5.91 \mathrm{E}-05$ \\
\hline 10 & 0 & 0 & 0 & 0 & 0 & 0 \\
\hline 11 & 0.3339 & -0.1763 & -0.00226 & $-2.38 \mathrm{E}-06$ & $-3.13 \mathrm{E}-06$ & 0.0001138 \\
\hline 12 & 0.3986 & -0.6458 & -0.00598 & $-5.43 \mathrm{E}-06$ & $6.3 \mathrm{E}-07$ & 0.0004788 \\
\hline 13 & 0.3465 & -1.3631 & -0.00633 & $-2.99 \mathrm{E}-06$ & $6.1 \mathrm{E}-07$ & 0.0005869 \\
\hline 14 & 0.2201 & -2.1728 & -0.00987 & $-5.7 \mathrm{E}-06$ & $-2 \mathrm{E}-07$ & 0.0006526 \\
\hline 15 & 0.108 & -2.9472 & -0.00947 & $-2.41 \mathrm{E}-06$ & $1.26 \mathrm{E}-06$ & 0.0005894 \\
\hline 16 & 0.0476 & -3.6036 & -0.01217 & $-4.79 \mathrm{E}-06$ & $-1.61 \mathrm{E}-06$ & 0.0004739 \\
\hline 17 & 0.0451 & -4.0865 & -0.01178 & $-2.86 \mathrm{E}-06$ & $2.01 \mathrm{E}-06$ & 0.0003153 \\
\hline 18 & 0.087 & -4.3601 & -0.0128 & $-3.84 \mathrm{E}-06$ & $-2.18 \mathrm{E}-06$ & 0.0001325 \\
\hline 19 & -0.4992 & -0.3107 & 0.00489 & $-1.24 \mathrm{E}-05$ & 4.739E-05 & -0.000431 \\
\hline 20 & -0.3078 & -0.6385 & -0.02019 & $-2.49 \mathrm{E}-05$ & $3.654 \mathrm{E}-05$ & -0.000478 \\
\hline 21 & -0.0296 & -1.2388 & -0.05359 & $-1.63 \mathrm{E}-06$ & $-2.29 \mathrm{E}-05$ & -0.000516 \\
\hline 22 & 0.2157 & -1.9472 & 0.00098 & $-1.21 \mathrm{E}-05$ & $2.676 \mathrm{E}-05$ & -0.000617 \\
\hline 23 & 0.4147 & -2.7553 & -0.07677 & $-1.88 \mathrm{E}-05$ & $-2.35 \mathrm{E}-05$ & -0.000554 \\
\hline 24 & 0.4645 & -3.407 & 0.01946 & 3.06E-06 & $1.821 \mathrm{E}-05$ & -0.00047 \\
\hline 25 & 0.4275 & -4.0079 & -0.08851 & $-2.95 \mathrm{E}-05$ & $-1.32 \mathrm{E}-05$ & -0.000315 \\
\hline 26 & 0.2746 & -4.283 & 0.02861 & $1.347 \mathrm{E}-05$ & 5.97E-06 & -0.000148 \\
\hline 27 & 0.0852 & -4.427 & -0.09157 & $-3.29 \mathrm{E}-05$ & 7.7E-07 & 0.0000353 \\
\hline 28 & -0.0984 & -4.1909 & 0.02772 & 1.299E-05 & $-8.08 \mathrm{E}-06$ & 0.0002187 \\
\hline 29 & -0.2348 & -3.829 & -0.08678 & $-2.82 \mathrm{E}-05$ & $1.447 \mathrm{E}-05$ & 0.0003763 \\
\hline 30 & -0.2486 & -3.1578 & 0.01697 & $2.23 \mathrm{E}-06$ & $-2.03 \mathrm{E}-05$ & 0.000523 \\
\hline 31 & -0.1714 & -2.4508 & -0.07321 & $-1.55 \mathrm{E}-05$ & $2.382 \mathrm{E}-05$ & 0.0005862 \\
\hline 32 & 0.048 & -1.6211 & -0.00389 & $-1.11 \mathrm{E}-05$ & $-2.85 \mathrm{E}-05$ & 0.0006374 \\
\hline 33 & 0.3055 & -0.9155 & -0.04687 & $2.14 \mathrm{E}-06$ & $1.265 \mathrm{E}-05$ & 0.0004725 \\
\hline 34 & 0.5168 & -0.4481 & -0.01514 & $-1.25 \mathrm{E}-05$ & $-3.38 \mathrm{E}-05$ & 0.0003008 \\
\hline 35 & 0.6193 & -0.2576 & 0.00232 & $1.06 \mathrm{E}-06$ & $-4.19 \mathrm{E}-05$ & 0.0002186 \\
\hline 36 & -0.4837 & -0.3277 & 0.02407 & $1.604 \mathrm{E}-05$ & $-1.83 \mathrm{E}-05$ & -0.000414 \\
\hline 37 & -0.3034 & -0.6398 & 0.02004 & $-2.17 \mathrm{E}-06$ & $1.928 \mathrm{E}-05$ & -0.000442 \\
\hline 38 & -0.0421 & -1.213 & -0.00611 & $1.616 \mathrm{E}-05$ & $-2.83 \mathrm{E}-05$ & -0.000548 \\
\hline 39 & 0.2323 & -1.9753 & 0.0426 & $5.09 \mathrm{E}-06$ & $2.792 \mathrm{E}-05$ & -0.000592 \\
\hline 40 & 0.3965 & -2.7058 & -0.03897 & $-1.76 \mathrm{E}-06$ & $-2.35 \mathrm{E}-05$ & -0.000572 \\
\hline 41 & 0.4802 & -3.4534 & 0.05352 & $1.798 \mathrm{E}-05$ & $1.893 \mathrm{E}-05$ & -0.000458 \\
\hline 42 & 0.4156 & -3.946 & -0.05749 & $-1.64 \mathrm{E}-05$ & $-1.28 \mathrm{E}-05$ & -0.000322 \\
\hline 43 & 0.2808 & -4.338 & 0.05783 & $2.526 \mathrm{E}-05$ & $6.21 \mathrm{E}-06$ & -0.000146 \\
\hline 44 & 0.0852 & -4.3617 & -0.06292 & $-2.15 \mathrm{E}-05$ & $9.6 \mathrm{E}-07$ & 0.0000362 \\
\hline 45 & -0.1046 & -4.2452 & 0.05727 & $2.495 \mathrm{E}-05$ & $-7.99 \mathrm{E}-06$ & 0.0002139 \\
\hline 46 & -0.2234 & -3.7692 & -0.05504 & -0.000015 & $1.445 \mathrm{E}-05$ & 0.0003854 \\
\hline 47 & -0.2637 & -3.2022 & 0.05191 & $1.676 \mathrm{E}-05$ & $-2 \mathrm{E}-05$ & 0.0005088 \\
\hline 48 & -0.1549 & -2.4059 & -0.03381 & $-1.68 \mathrm{E}-06$ & $2.304 \mathrm{E}-05$ & 0.0006056 \\
\hline
\end{tabular}




\begin{tabular}{l|llllll}
49 & 0.0337 & -1.6449 & 0.0387 & $5.24 \mathrm{E}-06$ & $-1.66 \mathrm{E}-05$ & 0.0006172 \\
50 & 0.3196 & -0.8867 & -0.01868 & $6.04 \mathrm{E}-06$ & $3.461 \mathrm{E}-05$ & 0.0004999 \\
51 & 0.5127 & -0.4484 & 0.01335 & $-1.6 \mathrm{E}-05$ & $-1.8 \mathrm{E}-05$ & 0.0002666 \\
52 & 0.6058 & -0.2711 & 0.02072 & 0.0000019 & $2.078 \mathrm{E}-05$ & 0.0002058
\end{tabular}

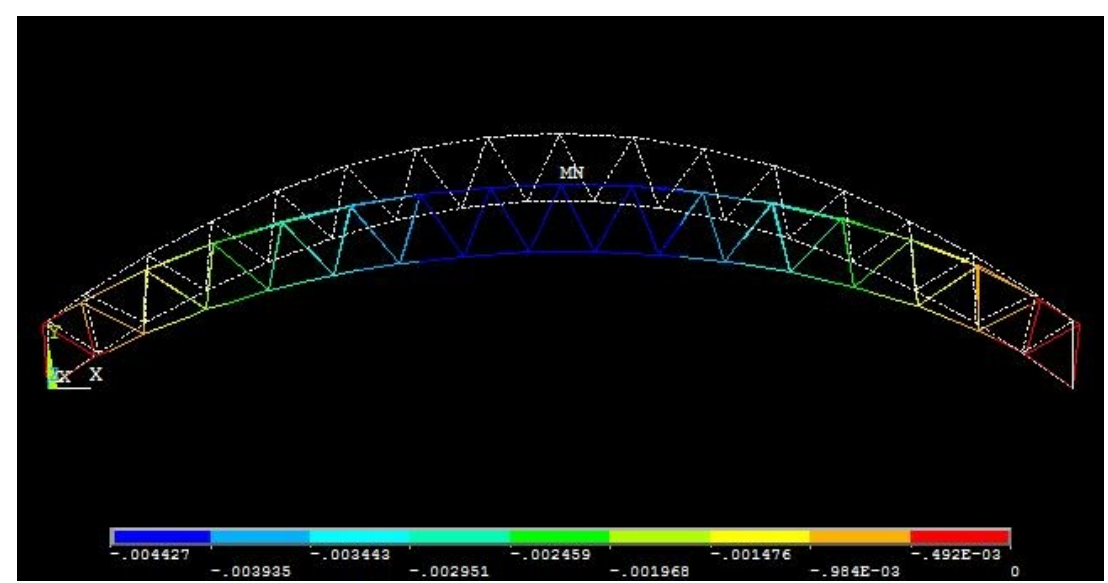

Figure 3.4.1.1y - axis deformation as plotted in ANSYS. The dotted line represents original beam and the colored line represents the deformed shape, with $M N$ showing the point of maximum negative deformation.

Table 3.4.1.2

\begin{tabular}{|c|c|c|c|c|c|c|}
\hline \multirow[b]{2}{*}{ NODE } & \multicolumn{6}{|c|}{ ANSYS RESULTS - 1} \\
\hline & $\mathbf{u x}$ & uy & $\mathbf{u z}$ & $\operatorname{rotx}$ & roty & rotz \\
\hline 1 & 0 & 0 & 0 & 0 & 0 & 0 \\
\hline 2 & -0.22564 & -0.33446 & -0.0021226 & $-1.7821 \mathrm{E}-06$ & $3.3536 \mathrm{E}-06$ & -0.00033126 \\
\hline 3 & -0.19967 & -0.93434 & -0.0056499 & $-4.541 \mathrm{E}-06$ & $-4.1938 \mathrm{E}-07$ & -0.00058366 \\
\hline 4 & -0.095734 & -1.7042 & -0.0057875 & $-1.7989 \mathrm{E}-06$ & $1.0725 \mathrm{E}-07$ & -0.00060128 \\
\hline 5 & 0.039067 & -2.4922 & -0.0097758 & $-5.489 \mathrm{E}-06$ & $6.8356 \mathrm{E}-07$ & -0.0006229 \\
\hline 6 & 0.14728 & -3.2188 & -0.0094128 & $-2.4019 \mathrm{E}-06$ & $-1.3987 \mathrm{E}-06$ & -0.00054342 \\
\hline 7 & 0.19936 & -3.81 & -0.012126 & $-4.7782 \mathrm{E}-06$ & 0.000001725 & -0.00041342 \\
\hline 8 & 0.19358 & -4.2154 & -0.011757 & $-2.9553 \mathrm{E}-06$ & -0.00000215 & -0.0002462 \\
\hline 9 & 0.14676 & -4.4038 & -0.012603 & $-3.7467 \mathrm{E}-06$ & $2.1507 \mathrm{E}-06$ & $-5.9053 \mathrm{E}-05$ \\
\hline 10 & 0 & 0 & 0 & 0 & 0 & 0 \\
\hline 11 & 0.33386 & -0.17629 & -0.0022573 & $-2.2874 \mathrm{E}-06$ & $-3.0847 \mathrm{E}-06$ & 0.00011375 \\
\hline 12 & 0.39857 & -0.64579 & -0.0058228 & $-5.359 \mathrm{E}-06$ & $7.256 \mathrm{E}-07$ & 0.00047871 \\
\hline 13 & 0.34652 & -1.363 & -0.006137 & $-2.9771 \mathrm{E}-06$ & $5.9531 \mathrm{E}-07$ & 0.00058691 \\
\hline 14 & 0.22008 & -2.1728 & -0.0096799 & $-5.7134 \mathrm{E}-06$ & -1.9299E-07 & 0.00065265 \\
\hline 15 & 0.10805 & -2.9471 & -0.0092805 & $-2.3965 \mathrm{E}-06$ & $1.2446 \mathrm{E}-06$ & 0.00058941 \\
\hline 16 & 0.047593 & -3.6036 & -0.011988 & $-4.7959 \mathrm{E}-06$ & $-1.6084 \mathrm{E}-06$ & 0.00047388 \\
\hline 17 & 0.045122 & -4.0865 & -0.011603 & $-2.8528 \mathrm{E}-06$ & 1.9959E-06 & 0.00031535 \\
\hline 18 & 0.087018 & -4.3601 & -0.012626 & $-3.8264 \mathrm{E}-06$ & $-2.1817 \mathrm{E}-06$ & 0.00013254 \\
\hline 19 & -0.49916 & -0.31067 & 0.0049061 & $-1.23 \mathrm{E}-05$ & 4.75E-05 & $-4.31 \mathrm{E}-04$ \\
\hline 20 & -0.30777 & -0.63844 & -0.020171 & $-2.49 \mathrm{E}-05$ & $3.65 \mathrm{E}-05$ & $-4.78 \mathrm{E}-04$ \\
\hline 21 & -0.029639 & -1.2387 & -0.053544 & $-1.70 \mathrm{E}-06$ & $-2.30 \mathrm{E}-05$ & $-5.16 \mathrm{E}-04$ \\
\hline 22 & 0.21571 & -1.9471 & 0.001043 & $-1.20 \mathrm{E}-05$ & $2.68 \mathrm{E}-05$ & $-6.17 \mathrm{E}-04$ \\
\hline 23 & 0.41467 & -2.7553 & -0.076684 & $-1.90 \mathrm{E}-05$ & $-2.36 \mathrm{E}-05$ & $-5.54 \mathrm{E}-04$ \\
\hline 24 & 0.46454 & -3.407 & 0.01958 & $3.27 \mathrm{E}-06$ & $1.82 \mathrm{E}-05$ & $-4.70 \mathrm{E}-04$ \\
\hline 25 & 0.42753 & -4.0079 & -0.088308 & $-2.97 E-05$ & $-1.32 \mathrm{E}-05$ & $-3.14 \mathrm{E}-04$ \\
\hline
\end{tabular}




\begin{tabular}{|l|cccccc|}
26 & 0.27463 & -4.283 & 0.028784 & $1.37 \mathrm{E}-05$ & $6.03 \mathrm{E}-06$ & $-1.48 \mathrm{E}-04$ \\
27 & 0.085214 & -4.427 & -0.091401 & $-3.32 \mathrm{E}-05$ & $7.66 \mathrm{E}-07$ & $3.53 \mathrm{E}-05$ \\
28 & -0.098432 & -4.1909 & 0.027901 & $1.32 \mathrm{E}-05$ & $-8.10 \mathrm{E}-06$ & $2.19 \mathrm{E}-04$ \\
29 & -0.23479 & -3.829 & -0.086607 & $-2.85 \mathrm{E}-05$ & $1.45 \mathrm{E}-05$ & $3.76 \mathrm{E}-04$ \\
30 & -0.2486 & -3.1578 & 0.017155 & $2.39 \mathrm{E}-06$ & $-2.03 \mathrm{E}-05$ & $5.23 \mathrm{E}-04$ \\
31 & -0.17137 & -2.4508 & -0.07303 & $-1.57 \mathrm{E}-05$ & $2.39 \mathrm{E}-05$ & $5.86 \mathrm{E}-04$ \\
32 & 0.047988 & -1.6211 & -0.0037051 & $-1.10 \mathrm{E}-05$ & $-2.85 \mathrm{E}-05$ & $6.37 \mathrm{E}-04$ \\
33 & 0.30555 & -0.91547 & -0.046676 & $2.16 \mathrm{E}-06$ & $1.26 \mathrm{E}-05$ & $4.72 \mathrm{E}-04$ \\
34 & 0.51683 & -0.44796 & -0.014921 & $-1.23 \mathrm{E}-05$ & $-3.39 \mathrm{E}-05$ & $3.01 \mathrm{E}-04$ \\
35 & 0.61929 & -0.25749 & 0.0024956 & $1.41 \mathrm{E}-06$ & $-4.21 \mathrm{E}-05$ & $2.19 \mathrm{E}-04$ \\
36 & -0.48376 & -0.32766 & 0.024082 & $1.60 \mathrm{E}-05$ & $-1.84 \mathrm{E}-05$ & $-4.14 \mathrm{E}-04$ \\
37 & -0.30345 & -0.63981 & 0.020069 & $-2.18 \mathrm{E}-06$ & $1.93 \mathrm{E}-05$ & $-4.42 \mathrm{E}-04$ \\
38 & -0.042163 & -1.213 & -0.006063 & $1.61 \mathrm{E}-05$ & $-2.84 \mathrm{E}-05$ & $-5.48 \mathrm{E}-04$ \\
39 & 0.23225 & -1.9753 & 0.042668 & $5.24 \mathrm{E}-06$ & $2.80 \mathrm{E}-05$ & $-5.92 \mathrm{E}-04$ \\
40 & 0.39644 & -2.7057 & -0.038886 & $-1.88 \mathrm{E}-06$ & $-2.35 \mathrm{E}-05$ & $-5.72 \mathrm{E}-04$ \\
41 & 0.4802 & -3.4534 & 0.053637 & $1.84 \mathrm{E}-05$ & $1.89 \mathrm{E}-05$ & $-4.58 \mathrm{E}-04$ \\
42 & 0.41561 & -3.9463 & -0.057236 & $-1.64 \mathrm{E}-05$ & $-1.29 \mathrm{E}-05$ & $-3.22 \mathrm{E}-04$ \\
43 & 0.28075 & -4.338 & 0.058002 & $2.57 \mathrm{E}-05$ & $6.29 \mathrm{E}-06$ & $-1.46 \mathrm{E}-04$ \\
44 & 0.085158 & -4.3617 & -0.062754 & $-2.17 \mathrm{E}-05$ & $9.52 \mathrm{E}-07$ & $3.62 \mathrm{E}-05$ \\
45 & -0.10461 & -4.2452 & 0.057451 & $2.53 \mathrm{E}-05$ & $-8.03 \mathrm{E}-06$ & $2.14 \mathrm{E}-04$ \\
46 & -0.22339 & -3.7692 & -0.054865 & $-1.52 \mathrm{E}-05$ & $1.45 \mathrm{E}-05$ & $3.85 \mathrm{E}-04$ \\
47 & -0.26371 & -3.2022 & 0.052095 & $1.70 \mathrm{E}-05$ & $-2.01 \mathrm{E}-05$ & $5.09 \mathrm{E}-04$ \\
48 & -0.15494 & -2.4058 & -0.03363 & $-1.82 \mathrm{E}-06$ & $2.31 \mathrm{E}-05$ & $6.06 \mathrm{E}-04$ \\
49 & 0.033689 & -1.6448 & 0.038886 & $5.37 \mathrm{E}-06$ & $-1.66 \mathrm{E}-05$ & $6.17 \mathrm{E}-04$ \\
50 & 0.31962 & -0.8866 & -0.018509 & $5.90 \mathrm{E}-06$ & $3.47 \mathrm{E}-05$ & $5.00 \mathrm{E}-04$ \\
51 & 0.51266 & -0.44855 & 0.013578 & $-1.59 \mathrm{E}-05$ & $-1.80 \mathrm{E}-05$ & $2.67 \mathrm{E}-04$ \\
52 & 0.60577 & -0.27115 & 0.020871 & $1.98 \mathrm{E}-06$ & $2.09 \mathrm{E}-05$ & $2.06 \mathrm{E}-04$ \\
\hline
\end{tabular}

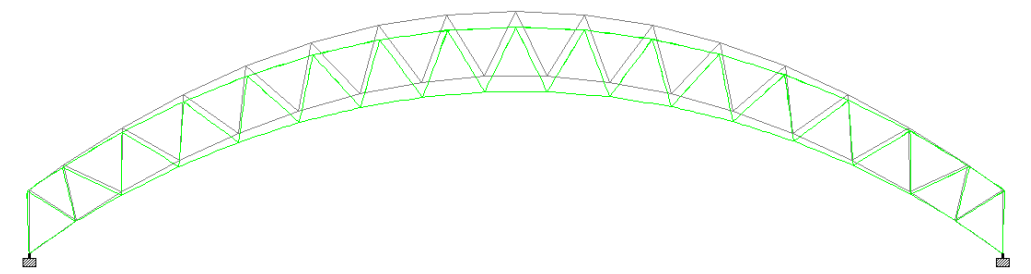

Figure 3.4.1.2 Displacement plotted in STAAD. The white line represents original beam and the green line represents the deformed shape.

Table 3.4.1.3

\begin{tabular}{|c|cccccc|}
\hline & \multicolumn{7}{|c|}{ STAAD RESULTS - 1 } \\
\hline NODE & $\mathbf{u x}$ & $\mathbf{u y}$ & $\mathbf{u z}$ & rotx & roty & rotz \\
\hline 1 & 0 & 0 & 0 & 0 & 0 & 0 \\
2 & -0.226 & -0.334 & -0.002 & 0 & 0 & -0.0003 \\
3 & -0.2 & -0.934 & -0.006 & 0 & 0 & -0.0006 \\
4 & -0.096 & -1.704 & -0.006 & 0 & 0 & -0.0006 \\
5 & 0.039 & -2.492 & -0.01 & 0 & 0 & -0.0006 \\
6 & 0.147 & -3.219 & -0.009 & 0 & 0 & -0.0005 \\
7 & 0.199 & -3.81 & -0.012 & 0 & 0 & -0.0004
\end{tabular}




\begin{tabular}{|c|c|c|c|c|c|c|}
\hline 8 & 0.194 & -4.215 & -0.012 & 0 & 0 & -0.0002 \\
\hline 9 & 0.147 & -4.404 & -0.013 & 0 & 0 & -0.0001 \\
\hline 10 & 0 & 0 & 0 & 0 & 0 & 0 \\
\hline 11 & 0.334 & -0.176 & -0.002 & 0 & 0 & 0.0001 \\
\hline 12 & 0.399 & -0.646 & -0.006 & 0 & 0 & 0.0005 \\
\hline 13 & 0.347 & -1.363 & -0.006 & 0 & 0 & 0.0006 \\
\hline 14 & 0.22 & -2.173 & -0.01 & 0 & 0 & 0.0007 \\
\hline 15 & 0.108 & -2.947 & -0.009 & 0 & 0 & 0.0006 \\
\hline 16 & 0.048 & -3.604 & -0.012 & 0 & 0 & 0.0005 \\
\hline 17 & 0.045 & -4.087 & -0.012 & 0 & 0 & 0.0003 \\
\hline 18 & 0.087 & -4.36 & -0.013 & 0 & 0 & 0.0001 \\
\hline 19 & -0.499 & -0.311 & 0.005 & 0 & 0 & -0.0004 \\
\hline 20 & -0.308 & -0.638 & -0.02 & 0 & 0 & -0.0005 \\
\hline 21 & -0.03 & -1.239 & -0.054 & 0 & 0 & -0.0005 \\
\hline 22 & 0.216 & -1.947 & 0.001 & 0 & 0 & -0.0006 \\
\hline 23 & 0.415 & -2.755 & -0.077 & 0 & 0 & -0.0006 \\
\hline 24 & 0.465 & -3.407 & 0.02 & 0 & 0 & -0.0005 \\
\hline 25 & 0.428 & -4.008 & -0.088 & 0 & 0 & -0.0003 \\
\hline 26 & 0.275 & -4.283 & 0.029 & 0 & 0 & -0.0001 \\
\hline 27 & 0.085 & -4.427 & -0.091 & 0 & 0 & 0 \\
\hline 28 & -0.098 & -4.191 & 0.028 & 0 & 0 & 0.0002 \\
\hline 29 & -0.235 & -3.829 & -0.087 & 0 & 0 & 0.0004 \\
\hline 30 & -0.249 & -3.158 & 0.017 & 0 & 0 & 0.0005 \\
\hline 31 & -0.171 & -2.451 & -0.073 & 0 & 0 & 0.0006 \\
\hline 32 & 0.048 & -1.621 & -0.004 & 0 & 0 & 0.0006 \\
\hline 33 & 0.306 & -0.915 & -0.047 & 0 & 0 & 0.0005 \\
\hline 34 & 0.517 & -0.448 & -0.015 & 0 & 0 & 0.0003 \\
\hline 35 & 0.619 & -0.257 & 0.002 & 0 & 0 & 0.0002 \\
\hline 36 & -0.484 & -0.328 & 0.024 & 0 & 0 & -0.0004 \\
\hline 37 & -0.303 & -0.64 & 0.02 & 0 & 0 & -0.0004 \\
\hline 38 & -0.042 & -1.213 & -0.006 & 0 & 0 & -0.0005 \\
\hline 39 & 0.232 & -1.975 & 0.043 & 0 & 0 & -0.0006 \\
\hline 40 & 0.396 & -2.706 & -0.039 & 0 & 0 & -0.0006 \\
\hline 41 & 0.48 & -3.453 & 0.054 & 0 & 0 & -0.0005 \\
\hline 42 & 0.416 & -3.946 & -0.057 & 0 & 0 & -0.0003 \\
\hline 43 & 0.281 & -4.338 & 0.058 & 0 & 0 & -0.0001 \\
\hline 44 & 0.085 & -4.362 & -0.063 & 0 & 0 & 0 \\
\hline 45 & -0.105 & -4.245 & 0.057 & 0 & 0 & 0.0002 \\
\hline 46 & -0.223 & -3.769 & -0.055 & 0 & 0 & 0.0004 \\
\hline 47 & -0.264 & -3.202 & 0.052 & 0 & 0 & 0.0005 \\
\hline 48 & -0.155 & -2.406 & -0.034 & 0 & 0 & 0.0006 \\
\hline 49 & 0.034 & -1.645 & 0.039 & 0 & 0 & 0.0006 \\
\hline 50 & 0.32 & -0.887 & -0.019 & 0 & 0 & 0.0005 \\
\hline 51 & 0.513 & -0.449 & 0.014 & 0 & 0 & 0.0003 \\
\hline 52 & 0.606 & -0.271 & 0.021 & 0 & 0 & 0.0002 \\
\hline
\end{tabular}

Analyzing the results in Tables 3.4.1.1 - 3.4.1.3, we can see that the STAAD results have a maximum of 4 significant digits, limiting their scope for comparison. However, the STAAD result for nearly every node matches exactly with that of MATLAB and ANSYS when they are rounded off up to the corresponding significant digit. The results of MATLAB and ANSYS are nearly identical for deflection along $x$ and $y$ axes and rotation about $z$ axis with errors below $0.05 \%$ for almost all their values. Here too, the small errors can be attributed to rounding off of significant digits, although the difference is of a single digit unlike that for STAAD. 
For deflection along $z$ axis and rotation about $x$ and $y$ axes, the error in the ANSYS results is substantial for nearly each node. While it clearly cannot be attributed to rounding off, the magnitude of error is quite random. The magnitude of this deformation and rotation is of the order of $10^{\wedge}-2 \mathrm{~mm}$ and $10^{\wedge}-5$ radian respectively while the difference in ANSYS and MATLAB values for the same, is of the order of $10^{\wedge}-4 \mathrm{~mm}$ and $10^{\wedge}-7$ radian respectively. Thus, for cases where the analysis does not require values of such a small order, this difference may be inconsequential. However, it is noted that the error in ANSYS result varies over a wide range. Further, no pattern can be established for the nodal distribution and magnitude of error. The conservative nature of some of the ANSYS values is also random in magnitude and distribution.

\subsubsection{For load case 2:}

Table 3.4.2.1

\begin{tabular}{|c|c|c|c|c|c|c|}
\hline \multirow[b]{2}{*}{ NODE } & \multicolumn{6}{|c|}{ MATLAB RESULTS - 2} \\
\hline & $\mathbf{u x}$ & uy & $\mathbf{u z}$ & rotx & roty & rotz \\
\hline 1 & 0 & 0 & 0 & 0 & 0 & 0 \\
\hline 2 & -0.1504 & -0.223 & -0.00143 & -0.00000121 & 0.00000224 & -0.0002208 \\
\hline 3 & -0.1331 & -0.6229 & -0.00379 & -0.00000302 & -0.00000026 & -0.0003891 \\
\hline 4 & -0.0638 & -1.1361 & -0.0039 & -0.00000121 & 0.00000008 & -0.0004009 \\
\hline 5 & 0.0261 & -1.6615 & -0.00657 & -0.00000366 & 0.00000048 & -0.0004153 \\
\hline 6 & 0.0982 & -2.1458 & -0.00634 & -0.00000161 & -0.00000095 & -0.0003623 \\
\hline 7 & 0.1329 & -2.54 & -0.00813 & -0.0000032 & 0.00000115 & -0.0002756 \\
\hline 8 & 0.1291 & -2.8102 & -0.00791 & -0.000002 & -0.0000014 & -0.0001642 \\
\hline 9 & 0.0978 & -2.9359 & -0.00851 & -0.00000251 & 0.00000145 & -0.0000394 \\
\hline 10 & 0 & 0 & 0 & 0 & 0 & 0 \\
\hline 11 & 0.2226 & -0.1175 & -0.00151 & -0.00000159 & -0.00000209 & 0.0000758 \\
\hline 12 & 0.2657 & -0.4305 & -0.00398 & -0.00000362 & 0.00000042 & 0.0003192 \\
\hline 13 & 0.231 & -0.9087 & -0.00422 & -0.00000199 & 0.00000041 & 0.0003913 \\
\hline 14 & 0.1467 & -1.4486 & -0.00658 & -0.0000038 & -0.00000013 & 0.0004351 \\
\hline 15 & 0.072 & -1.9648 & -0.00631 & -0.0000016 & 0.00000084 & 0.0003929 \\
\hline 16 & 0.0317 & -2.4024 & -0.00811 & -0.0000032 & -0.00000107 & 0.0003159 \\
\hline 17 & 0.0301 & -2.7244 & -0.00785 & -0.00000191 & 0.00000134 & 0.0002102 \\
\hline 18 & 0.058 & -2.9067 & -0.00853 & -0.00000256 & -0.00000146 & 0.0000884 \\
\hline 19 & -0.3328 & -0.2071 & 0.00326 & -0.00000829 & 0.00003159 & -0.0002872 \\
\hline 20 & -0.2052 & -0.4256 & -0.01346 & -0.00001659 & 0.00002436 & -0.0003186 \\
\hline 21 & -0.0198 & -0.8258 & -0.03573 & -0.00000109 & -0.00001528 & -0.0003443 \\
\hline 22 & 0.1438 & -1.2981 & 0.00065 & -0.00000806 & 0.00001784 & -0.0004116 \\
\hline 23 & 0.2764 & -1.8368 & -0.05118 & -0.00001253 & -0.00001563 & -0.0003692 \\
\hline 24 & 0.3097 & -2.2714 & 0.01297 & 0.00000204 & 0.00001214 & -0.000313 \\
\hline 25 & 0.285 & -2.672 & -0.05901 & -0.00001964 & -0.00000877 & -0.0002096 \\
\hline 26 & 0.1831 & -2.8553 & 0.01907 & 0.00000898 & 0.00000398 & -0.0000989 \\
\hline 27 & 0.0568 & -2.9513 & -0.06104 & -0.00002192 & 0.00000052 & 0.0000235 \\
\hline 28 & -0.0656 & -2.7939 & 0.01848 & 0.00000866 & -0.00000538 & 0.0001458 \\
\hline 29 & -0.1565 & -2.5527 & -0.05786 & -0.00001881 & 0.00000965 & 0.0002508 \\
\hline 30 & -0.1657 & -2.1052 & 0.01131 & 0.00000149 & -0.00001353 & 0.0003486 \\
\hline 31 & -0.1142 & -1.6339 & -0.04881 & -0.0000103 & 0.00001588 & 0.0003908 \\
\hline 32 & 0.032 & -1.0807 & -0.00259 & -0.00000741 & -0.00001897 & 0.0004249 \\
\hline 33 & 0.2037 & -0.6104 & -0.03125 & 0.00000143 & 0.00000843 & 0.000315 \\
\hline 34 & 0.3445 & -0.2987 & -0.0101 & -0.0000083 & -0.00002254 & 0.0002006 \\
\hline
\end{tabular}




\begin{tabular}{|l|cccccc|}
35 & 0.4128 & -0.1717 & 0.00155 & 0.0000007 & -0.00002793 & 0.0001457 \\
36 & -0.3225 & -0.2184 & 0.01605 & 0.00001069 & -0.00001218 & -0.0002757 \\
37 & -0.2023 & -0.4265 & 0.01336 & -0.000000145 & 0.00001285 & -0.0002946 \\
38 & -0.0281 & -0.8086 & -0.00407 & 0.00001078 & -0.00001886 & -0.0003652 \\
39 & 0.1548 & -1.3169 & 0.0284 & 0.00000339 & 0.00001862 & -0.0003946 \\
40 & 0.2643 & -1.8038 & -0.02598 & -0.00000117 & -0.00001566 & -0.0003816 \\
41 & 0.3201 & -2.3023 & 0.03568 & 0.00001199 & 0.00001262 & -0.000305 \\
42 & 0.2771 & -2.6307 & -0.03833 & -0.00001092 & -0.00000855 & -0.0002145 \\
43 & 0.1872 & -2.892 & 0.03855 & 0.00001684 & 0.00000414 & -0.0000971 \\
44 & 0.0568 & -2.9078 & -0.04194 & -0.00001432 & 0.00000064 & 0.0000241 \\
45 & -0.0697 & -2.8301 & 0.03818 & 0.00001663 & -0.00000533 & 0.0001426 \\
46 & -0.1489 & -2.5128 & -0.03669 & -0.00001 & 0.00000964 & 0.0002569 \\
47 & -0.1758 & -2.1348 & 0.03461 & 0.00001117 & -0.00001332 & 0.0003392 \\
48 & -0.1033 & -1.6039 & -0.02254 & -0.00000112 & 0.00001536 & 0.0004037 \\
49 & 0.0225 & -1.0966 & 0.0258 & 0.00000349 & -0.00001105 & 0.0004115 \\
50 & 0.2131 & -0.5911 & -0.01246 & 0.00000403 & 0.00002308 & 0.0003333 \\
51 & 0.3418 & -0.2989 & 0.0089 & -0.00001065 & -0.00001201 & 0.0001777 \\
52 & 0.4039 & -0.1807 & 0.01381 & 0.00000126 & 0.00001386 & 0.0001372 \\
\hline
\end{tabular}

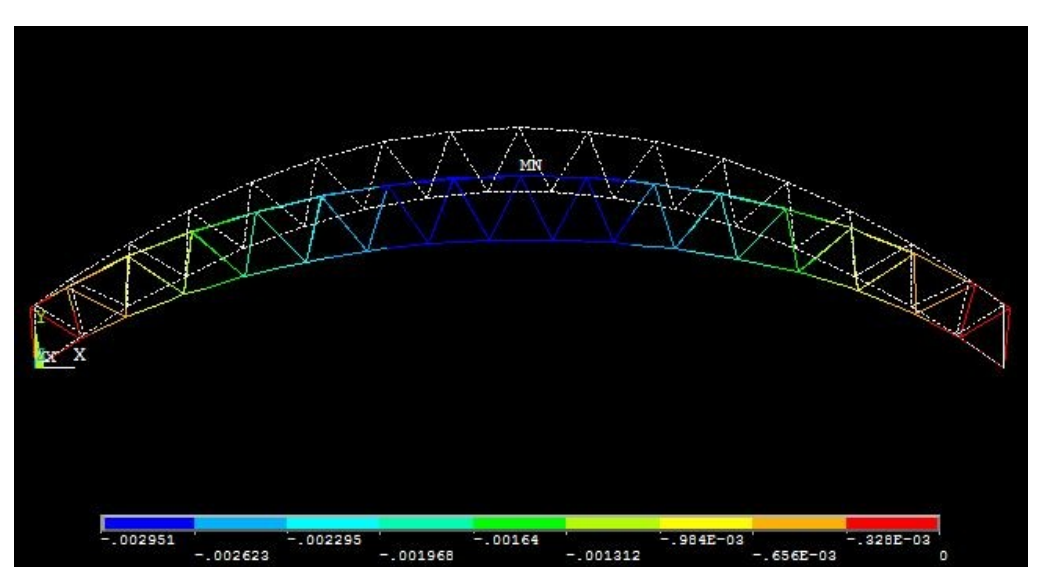

Figure 3.4.2.1y - axis deformation as plotted in ANSYS. The dotted line represents original beam and the colored line represents the deformed shape, with $M N$ showing the point of maximum negative deformation.

Table 3.4.2.2

\begin{tabular}{|c|cccccc}
\hline & \multicolumn{7}{c|}{ ANSYS RESULTS- 2 } \\
\hline NODE & $\mathbf{u x}$ & $\mathbf{u y}$ & $\mathbf{u z}$ & rotx & roty & rotz \\
\hline 1 & 0 & 0 & 0 & 0 & 0 & 0 \\
2 & -0.15043 & -0.22297 & -0.00142 & $-1.19 \mathrm{E}-06$ & $2.24 \mathrm{E}-06$ & $-2.21 \mathrm{E}-04$ \\
3 & -0.13311 & -0.62289 & -0.00377 & $-3.03 \mathrm{E}-06$ & $-2.80 \mathrm{E}-07$ & $-3.89 \mathrm{E}-04$ \\
4 & -0.06382 & -1.1361 & -0.00386 & $-1.20 \mathrm{E}-06$ & $7.15 \mathrm{E}-08$ & $-4.01 \mathrm{E}-04$ \\
5 & 0.026044 & -1.6615 & -0.00652 & $-3.66 \mathrm{E}-06$ & $4.56 \mathrm{E}-07$ & $-4.15 \mathrm{E}-04$ \\
6 & 0.098188 & -2.1458 & -0.00628 & $-1.60 \mathrm{E}-06$ & $-9.32 \mathrm{E}-07$ & $-3.62 \mathrm{E}-04$ \\
7 & 0.13291 & -2.54 & -0.00808 & $-3.19 \mathrm{E}-06$ & $1.15 \mathrm{E}-06$ & $-2.76 \mathrm{E}-04$ \\
8 & 0.12906 & -2.8102 & -0.00784 & $-1.97 \mathrm{E}-06$ & $-1.43 \mathrm{E}-06$ & $-1.64 \mathrm{E}-04$ \\
9 & 0.097842 & -2.9358 & -0.0084 & $-2.50 \mathrm{E}-06$ & $1.43 \mathrm{E}-06$ & $-3.94 \mathrm{E}-05$ \\
10 & 0 & 0 & 0 & 0 & 0 & 0
\end{tabular}




\begin{tabular}{|c|c|c|c|c|c|c|}
\hline 11 & 0.22258 & -0.11753 & -0.0015 & $-1.52 \mathrm{E}-06$ & $-2.06 \mathrm{E}-06$ & $7.58 \mathrm{E}-05$ \\
\hline 12 & 0.26571 & -0.43052 & -0.00388 & $-3.57 \mathrm{E}-06$ & 4.84E-07 & $3.19 \mathrm{E}-04$ \\
\hline 13 & 0.23101 & -0.9087 & -0.00409 & $-1.98 \mathrm{E}-06$ & 3.97E-07 & $3.91 \mathrm{E}-04$ \\
\hline 14 & 0.14672 & -1.4485 & -0.00645 & $-3.81 \mathrm{E}-06$ & $-1.29 \mathrm{E}-07$ & $4.35 \mathrm{E}-04$ \\
\hline 15 & 0.072035 & -1.9648 & -0.00619 & $-1.60 \mathrm{E}-06$ & $8.30 \mathrm{E}-07$ & $3.93 \mathrm{E}-04$ \\
\hline 16 & 0.031729 & -2.4024 & -0.00799 & $-3.20 \mathrm{E}-06$ & $-1.07 \mathrm{E}-06$ & $3.16 \mathrm{E}-04$ \\
\hline 17 & 0.030081 & -2.7244 & -0.00774 & $-1.90 \mathrm{E}-06$ & $1.33 \mathrm{E}-06$ & $2.10 \mathrm{E}-04$ \\
\hline 18 & 0.058012 & -2.9067 & -0.00842 & $-2.55 \mathrm{E}-06$ & $-1.45 \mathrm{E}-06$ & $8.84 \mathrm{E}-05$ \\
\hline 19 & -0.33277 & -0.20711 & 0.003271 & $-8.18 \mathrm{E}-06$ & $3.17 \mathrm{E}-05$ & $-2.87 \mathrm{E}-04$ \\
\hline 20 & -0.20518 & -0.42563 & -0.01345 & $-1.66 \mathrm{E}-05$ & $2.44 \mathrm{E}-05$ & $-3.19 \mathrm{E}-04$ \\
\hline 21 & -0.01976 & -0.82583 & -0.0357 & $-1.13 \mathrm{E}-06$ & $-1.53 \mathrm{E}-05$ & $-3.44 \mathrm{E}-04$ \\
\hline 22 & 0.14381 & -1.2981 & 0.000695 & $-8.00 \mathrm{E}-06$ & $1.79 \mathrm{E}-05$ & $-4.12 \mathrm{E}-04$ \\
\hline 23 & 0.27644 & -1.8368 & -0.05112 & $-1.27 \mathrm{E}-05$ & $-1.57 \mathrm{E}-05$ & $-3.69 \mathrm{E}-04$ \\
\hline 24 & 0.30969 & -2.2713 & 0.013053 & $2.18 \mathrm{E}-06$ & $1.21 \mathrm{E}-05$ & $-3.13 \mathrm{E}-04$ \\
\hline 25 & 0.28502 & -2.6719 & -0.05887 & $-1.98 \mathrm{E}-05$ & $-8.82 \mathrm{E}-06$ & $-2.10 \mathrm{E}-04$ \\
\hline 26 & 0.18308 & -2.8553 & 0.019189 & $9.15 \mathrm{E}-06$ & $4.02 \mathrm{E}-06$ & $-9.89 \mathrm{E}-05$ \\
\hline 27 & 0.05681 & -2.9513 & -0.06093 & $-2.22 \mathrm{E}-05$ & $5.11 \mathrm{E}-07$ & $2.35 \mathrm{E}-05$ \\
\hline 28 & -0.06562 & -2.7939 & 0.018601 & 8.81E-06 & $-5.40 \mathrm{E}-06$ & $1.46 \mathrm{E}-04$ \\
\hline 29 & -0.15653 & -2.5527 & -0.05774 & $-1.90 \mathrm{E}-05$ & $9.69 \mathrm{E}-06$ & $2.51 \mathrm{E}-04$ \\
\hline 30 & -0.16573 & -2.1052 & 0.011437 & $1.59 \mathrm{E}-06$ & $-1.36 \mathrm{E}-05$ & $3.49 \mathrm{E}-04$ \\
\hline 31 & -0.11425 & -1.6339 & -0.04869 & $-1.04 \mathrm{E}-05$ & $1.59 \mathrm{E}-05$ & $3.91 \mathrm{E}-04$ \\
\hline 32 & 0.031992 & -1.0807 & -0.00247 & $-7.34 \mathrm{E}-06$ & $-1.90 \mathrm{E}-05$ & $4.25 \mathrm{E}-04$ \\
\hline 33 & 0.2037 & -0.61032 & -0.03112 & $1.44 \mathrm{E}-06$ & 8.41E-06 & $3.15 \mathrm{E}-04$ \\
\hline 34 & 0.34455 & -0.29864 & -0.00995 & $-8.18 \mathrm{E}-06$ & $-2.26 \mathrm{E}-05$ & $2.01 \mathrm{E}-04$ \\
\hline 35 & 0.41286 & -0.17166 & 0.001664 & $9.40 \mathrm{E}-07$ & $-2.81 \mathrm{E}-05$ & $1.46 \mathrm{E}-04$ \\
\hline 36 & -0.32251 & -0.21844 & 0.016054 & $1.06 \mathrm{E}-05$ & $-1.22 \mathrm{E}-05$ & $-2.76 \mathrm{E}-04$ \\
\hline 37 & -0.2023 & -0.42654 & 0.013379 & $-1.45 \mathrm{E}-06$ & $1.28 \mathrm{E}-05$ & $-2.95 \mathrm{E}-04$ \\
\hline 38 & -0.02811 & -0.80863 & -0.00404 & $1.07 \mathrm{E}-05$ & $-1.89 \mathrm{E}-05$ & $-3.65 \mathrm{E}-04$ \\
\hline 39 & 0.15483 & -1.3169 & 0.028446 & $3.49 \mathrm{E}-06$ & $1.87 \mathrm{E}-05$ & $-3.95 \mathrm{E}-04$ \\
\hline 40 & 0.2643 & -1.8038 & -0.02592 & $-1.25 \mathrm{E}-06$ & $-1.57 \mathrm{E}-05$ & $-3.82 \mathrm{E}-04$ \\
\hline 41 & 0.32014 & -2.3023 & 0.035758 & $1.22 \mathrm{E}-05$ & $1.26 \mathrm{E}-05$ & $-3.05 \mathrm{E}-04$ \\
\hline 42 & 0.27707 & -2.6309 & -0.03816 & $-1.09 \mathrm{E}-05$ & $-8.61 \mathrm{E}-06$ & $-2.14 \mathrm{E}-04$ \\
\hline 43 & 0.18717 & -2.892 & 0.038668 & $1.71 \mathrm{E}-05$ & 4.20E-06 & $-9.70 \mathrm{E}-05$ \\
\hline 44 & 0.056772 & -2.9078 & -0.04184 & $-1.45 \mathrm{E}-05$ & $6.35 \mathrm{E}-07$ & $2.41 \mathrm{E}-05$ \\
\hline 45 & -0.06974 & -2.8301 & 0.038301 & $1.69 \mathrm{E}-05$ & $-5.35 \mathrm{E}-06$ & $1.43 \mathrm{E}-04$ \\
\hline 46 & -0.14893 & -2.5128 & -0.03658 & $-1.01 \mathrm{E}-05$ & $9.66 \mathrm{E}-06$ & $2.57 \mathrm{E}-04$ \\
\hline 47 & -0.17581 & -2.1348 & 0.03473 & $1.14 \mathrm{E}-05$ & $-1.34 \mathrm{E}-05$ & $3.39 \mathrm{E}-04$ \\
\hline 48 & -0.1033 & -1.6039 & -0.02242 & $-1.21 \mathrm{E}-06$ & $1.54 \mathrm{E}-05$ & 4.04E-04 \\
\hline 49 & 0.02246 & -1.0965 & 0.025924 & $3.58 \mathrm{E}-06$ & $-1.11 \mathrm{E}-05$ & $4.11 \mathrm{E}-04$ \\
\hline 50 & 0.21308 & -0.59107 & -0.01234 & $3.93 \mathrm{E}-06$ & $2.31 \mathrm{E}-05$ & $3.33 \mathrm{E}-04$ \\
\hline 51 & 0.34178 & -0.29903 & 0.009052 & $-1.06 \mathrm{E}-05$ & $-1.20 \mathrm{E}-05$ & $1.78 \mathrm{E}-04$ \\
\hline 52 & 0.40385 & -0.18077 & 0.013914 & $1.32 \mathrm{E}-06$ & $1.39 \mathrm{E}-05$ & $1.37 \mathrm{E}-04$ \\
\hline
\end{tabular}




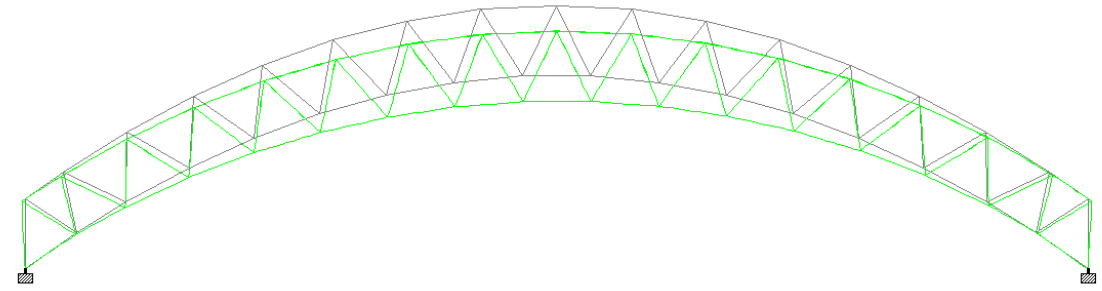

Figure 3.4.6 Displacement plotted in STAAD. The white line represents original beam and the green line represents the deformed shape.

Table 3.4.2.3

\begin{tabular}{|c|c|c|c|c|c|c|}
\hline \multirow[b]{2}{*}{ NODE } & \multicolumn{6}{|c|}{ STAAD RESULTS - 2} \\
\hline & ux & uy & $\mathbf{u z}$ & rotx & roty & rotz \\
\hline 1 & 0 & 0 & 0 & 0 & 0 & 0 \\
\hline 2 & -0.15 & -0.223 & -0.001 & 0 & 0 & -0.0002 \\
\hline 3 & -0.133 & -0.623 & -0.004 & 0 & 0 & -0.0004 \\
\hline 4 & -0.064 & -1.136 & -0.004 & 0 & 0 & -0.0004 \\
\hline 5 & 0.026 & -1.661 & -0.007 & 0 & 0 & -0.0004 \\
\hline 6 & 0.098 & -2.146 & -0.006 & 0 & 0 & -0.0004 \\
\hline 7 & 0.133 & -2.54 & -0.008 & 0 & 0 & -0.0003 \\
\hline 8 & 0.129 & -2.81 & -0.008 & 0 & 0 & -0.0002 \\
\hline 9 & 0.098 & -2.936 & -0.008 & 0 & 0 & 0 \\
\hline 10 & 0 & 0 & 0 & 0 & 0 & 0 \\
\hline 11 & 0.223 & -0.118 & -0.002 & 0 & 0 & 0.0001 \\
\hline 12 & 0.266 & -0.431 & -0.004 & 0 & 0 & 0.0003 \\
\hline 13 & 0.231 & -0.909 & -0.004 & 0 & 0 & 0.0004 \\
\hline 14 & 0.147 & -1.449 & -0.006 & 0 & 0 & 0.0004 \\
\hline 15 & 0.072 & -1.965 & -0.006 & 0 & 0 & 0.0004 \\
\hline 16 & 0.032 & -2.402 & -0.008 & 0 & 0 & 0.0003 \\
\hline 17 & 0.03 & -2.724 & -0.008 & 0 & 0 & 0.0002 \\
\hline 18 & 0.058 & -2.907 & -0.008 & 0 & 0 & 0.0001 \\
\hline 19 & -0.333 & -0.207 & 0.003 & 0 & 0 & -0.0003 \\
\hline 20 & -0.205 & -0.426 & -0.013 & 0 & 0 & -0.0003 \\
\hline 21 & -0.02 & -0.826 & -0.036 & 0 & 0 & -0.0003 \\
\hline 22 & 0.144 & -1.298 & 0.001 & 0 & 0 & -0.0004 \\
\hline 23 & 0.276 & -1.837 & -0.051 & 0 & 0 & -0.0004 \\
\hline 24 & 0.31 & -2.271 & 0.013 & 0 & 0 & -0.0003 \\
\hline 25 & 0.285 & -2.672 & -0.059 & 0 & 0 & -0.0002 \\
\hline 26 & 0.183 & -2.855 & 0.019 & 0 & 0 & -0.0001 \\
\hline 27 & 0.057 & -2.951 & -0.061 & 0 & 0 & 0 \\
\hline 28 & -0.066 & -2.794 & 0.019 & 0 & 0 & 0.0001 \\
\hline 29 & -0.157 & -2.553 & -0.058 & 0 & 0 & 0.0003 \\
\hline 30 & -0.166 & -2.105 & 0.011 & 0 & 0 & 0.0003 \\
\hline 31 & -0.114 & -1.634 & -0.049 & 0 & 0 & 0.0004 \\
\hline 32 & 0.032 & -1.081 & -0.002 & 0 & 0 & 0.0004 \\
\hline 33 & 0.204 & -0.61 & -0.031 & 0 & 0 & 0.0003 \\
\hline
\end{tabular}




\begin{tabular}{|c|cccccc|}
34 & 0.345 & -0.299 & -0.01 & 0 & 0 & 0.0002 \\
35 & 0.413 & -0.172 & 0.002 & 0 & 0 & 0.0001 \\
36 & -0.323 & -0.218 & 0.016 & 0 & 0 & -0.0003 \\
37 & -0.202 & -0.427 & 0.013 & 0 & 0 & -0.0003 \\
38 & -0.028 & -0.809 & -0.004 & 0 & 0 & -0.0004 \\
39 & 0.155 & -1.317 & 0.028 & 0 & 0 & -0.0004 \\
40 & 0.264 & -1.804 & -0.026 & 0 & 0 & -0.0004 \\
41 & 0.32 & -2.302 & 0.036 & 0 & 0 & -0.0003 \\
42 & 0.277 & -2.631 & -0.038 & 0 & 0 & -0.0002 \\
43 & 0.187 & -2.892 & 0.039 & 0 & 0 & -0.0001 \\
44 & 0.057 & -2.908 & -0.042 & 0 & 0 & 0 \\
45 & -0.07 & -2.83 & 0.038 & 0 & 0 & 0.0001 \\
46 & -0.149 & -2.513 & -0.037 & 0 & 0 & 0.0003 \\
47 & -0.176 & -2.135 & 0.035 & 0 & 0 & 0.0003 \\
48 & -0.103 & -1.604 & -0.022 & 0 & 0 & 0.0004 \\
49 & 0.022 & -1.097 & 0.026 & 0 & 0 & 0.0004 \\
50 & 0.213 & -0.591 & -0.012 & 0 & 0 & 0.0003 \\
51 & 0.342 & -0.299 & 0.009 & 0 & 0 & 0.0002 \\
52 & 0.404 & -0.181 & 0.014 & 0 & 0 & 0.0001 \\
\hline
\end{tabular}

In the second load case, while the obvious observation is the lower values of deformation and rotation as compared to those of the first case, the errors in the ANSYS results are very similar to those observed in the first case. The observations regarding the STAAD results are also same as that of the first case. The high error values of ANSYS for both cases are nearly identical and on the same nodes in spite of the different loads.

\section{Discussion And Conclusion}

Analyzing the data in section 3, we can conclude that the incidence of error in ANSYS and STAAD increases as the complexity of the structure increases. STAAD, for the purpose of analyzing structures, limits its results to the fourth decimal point and to the units of centimeter and radian. Practical applications of these results do not require them to be any more detailed. While some of the ANSYS results may have substantial error, the absolute differences in their values with respect to those of MATLAB are extremely small. In the section 3.4, the ANSYS errors in the two load cases were nearly the same, displaying a consistency in the results. It also shows that the fundamental difference lies within the stiffness matrix of ANSYS and MATLAB. The number of significant digits of the ANSYS results is higher than that of the MATLAB results. Thus, the errors in the ANSYS results may have arisen due to cumulative rounding off effect while computing the stiffness matrix and its inverse in MATLAB, which when operated on gives the erroneous displacement matrix. As the complexity of the structure increases i.e. the number of nodes and elements increases, the incidence of error in the ANSYS solution may increase due to its cumulative nature.

Since all the three methods detailed in this discussion use the same method to find the deformation of a structure, their solutions are same to a certain degree. Wherever a more detailed solution is required, MATLAB or ANSYS may be used. None of the methods may be termed as better or worse on the basis of conservative results due to inadequate proof of the same.

Acknowledgment

The authors would like to thank AdityaVaidya for the initial idea of the discussion detailed in this paper.

References

[1] S.S. Rao: The Finite Element Method in Engineering $\left(4^{\text {th }}\right.$ Ed., Elsevier Science \& Technology Books, 2004) 